\title{
Localization Requirements for Autonomous Vehicles
}

\author{
Tyler G. R. Reid, Sarah E. Houts, Robert Cammarata, \\ Graham Mills, Siddharth Agarwal, Ankit Vora, and Gaurav Pandey
}

\begin{abstract}
Autonomous vehicles require precise knowledge of their position and orientation in all weather and traffic conditions for path planning, perception, control, and general safe operation. Here we derive these requirements for autonomous vehicles based on first principles. We begin with the safety integrity level, defining the allowable probability of failure per hour of operation based on desired improvements on road safety today. This draws comparisons with the localization integrity levels required in aviation and rail where similar numbers are derived at $10^{-8}$ probability of failure per hour of operation. We then define the geometry of the problem, where the aim is to maintain knowledge that the vehicle is within its lane and to determine what road level it is on. Longitudinal, lateral, and vertical localization error bounds (alert limits) and 95\% accuracy requirements are derived based on US road geometry standards (lane width, curvature, and vertical clearance) and allowable vehicle dimensions. For passenger vehicles operating on freeway roads, the result is a required lateral error bound of $0.57 \mathrm{~m}$ $(0.20 \mathrm{~m}, 95 \%)$, a longitudinal bound of $1.40 \mathrm{~m}(0.48 \mathrm{~m}, 95 \%)$, a vertical bound of $1.30 \mathrm{~m}(0.43 \mathrm{~m}, 95 \%)$, and an attitude bound in each direction of $1.50 \mathrm{deg}(0.51 \mathrm{deg}, 95 \%)$. On local streets, the road geometry makes requirements more stringent where lateral and longitudinal error bounds of $0.29 \mathrm{~m}(0.10 \mathrm{~m}, 95 \%)$ are needed with an orientation requirement of $0.50 \mathrm{deg}(0.17 \mathrm{deg}, 95 \%)$.
\end{abstract}

Index Terms-Autonomous vehicles, automated driving, localization, positioning, requirements, safety, integrity

\section{INTRODUCTION}

$\mathbf{T}$ HE challenge facing localization for autonomous systems in terms of required accuracy and reliability at scale is unprecedented. As will be shown, autonomous vehicles require decimeter-level positioning for highway operation and nearcentimeter level for operation on local and residential streets. These requirements stem from one goal: ensure that the vehicle knows it is within its lane. Horizontally, this is broken down by lateral (side-to-side) and longitudinal (forward-backward) components. Vertically, the vehicle must know what road level it is on when located among multi-level roads. At any given time, the vehicle will have an estimate of its maximum position error in each direction. These are known as protection levels and are depicted in Figure 11. The maximum allowable protection levels in each direction to ensure safe operation are known as the alert limits. These alert limits are design

T. G. R. Reid and G. Pandey are with Research and Advanced Engineering, Ford Motor Company, Palo Alto, CA 94304, e-mail: \{treid21, gpandey2\}@ford.com

S. E. Houts, and G. Mills are with Ford Autonomous Vehicles LLC, Palo Alto, CA 94304, e-mail: \{shouts, gmills47\} @ford.com

Robert Cammarata, S. Agarwal, and A. Vora are with Ford Autonomous Vehicles LLC, Dearborn, MI 48124, e-mail: \{rcammar1, sagarw20, avora3\}@ford.com

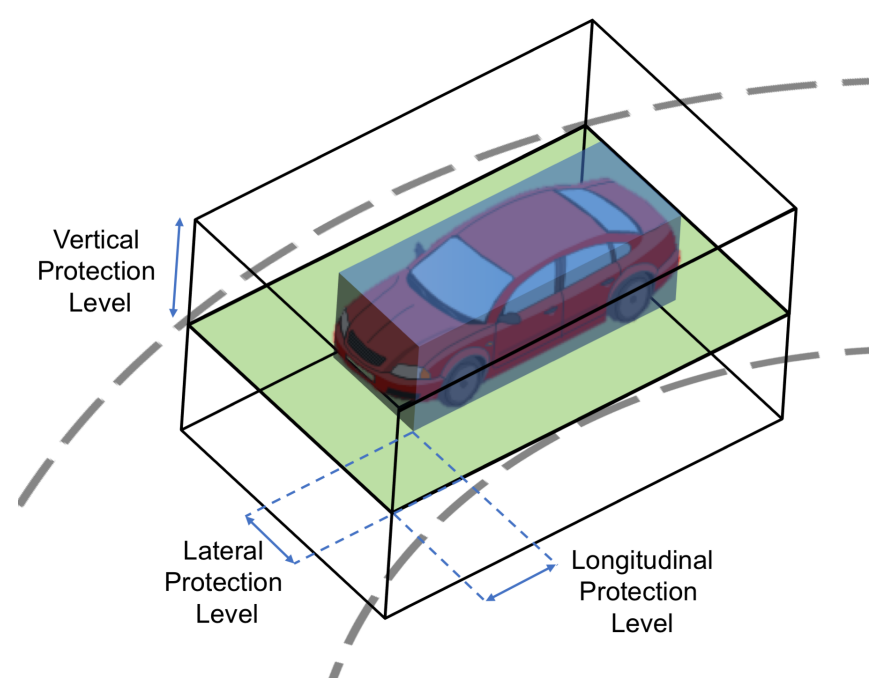

Fig. 1. Definition of localization protection levels for automotive applications.

variables; in our case they need to be sufficiently small to ensure that the vehicle stays within its lane at all times. If the protection level is larger than the alert limit at any given time, there is less certainty the vehicle will remain within its lane. These bounds will be shown to be a function of vehicle dimensions (length and width) along with road geometry standards (lane width and curvature).

The challenge of decimeter location accuracy is put in perspective by Table $\mathrm{I}$ which shows the progress in localization throughout the last century [1] . In the early 1900s, the state of the art were the tools used for navigation at sea. This consisted of a sextant to measure latitude by the stars and a precise mechanical clock known as a marine chronometer to measure longitude. Combined, these sensors gave rise to approximately $3 \mathrm{~km}$ of position accuracy at sea [2]. The Second World War accelerated the use of radio in navigation to support emerging aviation operations. Air navigation was needed in all weather in real-time. Land-based radio beacons were developed which gave rise to approximately 500 meters of accuracy but this required proximity to this infrastructure's limited range [3][5]. In the 1960s, the first satellite navigation system, Transit, came online. Operated by the US Navy, Transit offered 25 meters of accuracy, supporting the localization requirements of Polaris ballistic missile submarines [6]-[8]. This system had only a handful of satellites in low Earth orbit, resulting in sometimes an hour or more to obtain a position fix. In the 
TABLE I

EVOLUTION OF LOCALIZATION ACCURACY IN THE LAST CENTURY. BASED ON DATA FROM [1]-9].

\begin{tabular}{lccccl}
\hline System & Years Active & Horizontal Accuracy $[\mathrm{m}]$ & Latency & Fix Type & Coverage \\
\hline Celestial / Chronometry & $1770-1920$ & 3,200 & Hours & 2D & Global but not available when overcast \\
LORAN-C & $1957-2010$ & 460 & None & 2D & North America, Europe, Pacific Rim \\
Transit & $1964-1996$ & 25 & $30-100$ min & 2D & Global \\
GPS & $1995-$ Present & 3 & None & 3D & Global \\
\hline
\end{tabular}
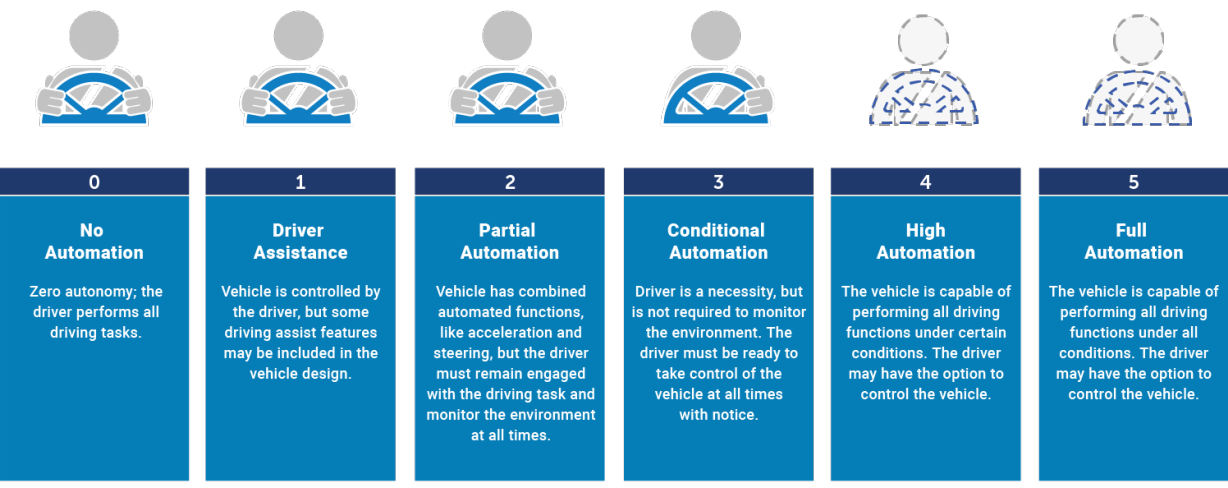

Fig. 2. Society of Automotive Engineers (SAE) levels of road vehicle autonomy (source: National Highway Traffic Safety Administration).

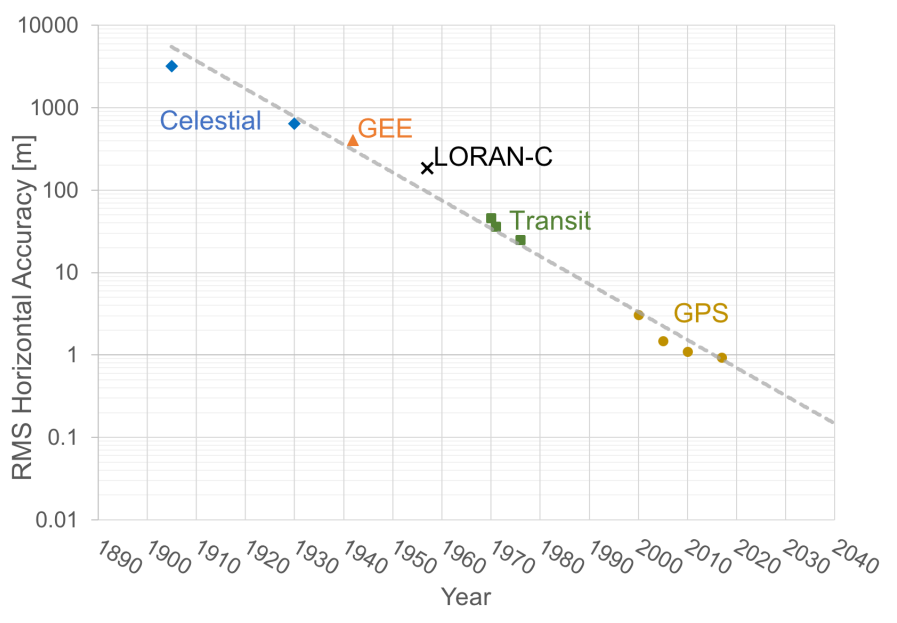

Fig. 3. Historical trend in widely available RMS position accuracy from a variety of technologies. Compiled by the authors based on data from [2]-[12].

1990s, the Global Positioning System (GPS) came online, now offering 1-5 meters of accuracy in open skies everywhere on Earth in real-time [12], [13]. Figure 3 shows this progression as a clear trend in the last century: an order of magnitude increase in localization accuracy every 30 years. This predicts the 2020s to be the first decade of the decimeter. As will be shown here, we are well poised, as this trend is towards the needs of autonomous vehicle operation.

Figure 2 shows the Society of Automotive Engineers (SAE) levels of vehicle autonomy [14]. Level 0 represents no automation where the driver is responsible for all aspects of driving and exemplifies most vehicles up to approximately the 1970s. Level 1 represents some driver assistance features for either braking / throttle or steering but the driver is still expected to monitor and control the vehicle. This includes features like cruise control and Anti-lock Braking Systems (ABS). Level 2 is partial automation, where the human driver is responsible for monitoring the scene and the system is responsible for some dynamic driving tasks including lateral and longitudinal motion (steering, propulsion, and braking). The human driver must be ready to take over dynamic driving tasks immediately when the driver determines the system is incapable. Examples of level 2 systems are Tesla's Autopilot released in 2014 and General Motor's Super Cruise released in 2017 [15], [16]. Level 3 is conditional automation, meaning that in certain circumstances, the vehicle is within its Operational Design Domain (ODD). The system is responsible for monitoring the scene and dynamic driving tasks including lateral and longitudinal motion (steering, propulsion, and braking). The human driver must be ready to take over dynamic driving tasks within a defined time when the system determines it's incapable or the vehicle is outside of its ODD and notifies the driver. Level 4 is highly automated where the system can perform all dynamic driving tasks within its ODD. This mode of operation maybe geofenced to areas with appropriate supporting infrastructure (e.g. maps and connectivity) and may further be restricted to certain weather conditions. In 2018, this represents largely research vehicles such as Waymo's selfdriving minivan which is gearing towards initial ride-sharing service [17]. Level 5 is full automation, where the vehicle is capable of performing all dynamic driving tasks in all areas and under all conditions.

Positioning accuracy requirements for connected vehicle (V2X) applications have been previously broken down by Basnayake et al. [18] into the categories of which-road $(<5$ meters), which-lane $(<1.5$ meters $)$, and where-in-lane $(<1.0$ meter $)$ based on the desired function or operation. The National Highway Safety Administration (NHTSA) has, as 
part of its Federal Motor Vehicle Safety Standards in V2V Communications, determined that position must be reported to an accuracy of 1.5 meters ( $1 \sigma$ or $68 \%$ ) as this is tentatively believed to provide lane-level information for safety applications [19]. Vehicle positioning requirements were further developed by Stephenson [20] who explored the Required Navigation Performance (RNP) for Advanced Driver Assistance Systems (ADAS) and automated driving. Stephenson added the functional category of active vehicle control requiring an accuracy better than 0.1 meters.

In this paper, we focus on full autonomous operation which requires the accuracy needed for active control. In this context, 'autonomous vehicle' will refer to level 3+ systems, though some of what is shown here can also be applied to level 2. The process followed to develop these requirements is outlined in Figure 4 We begin with defining the statistics of the problem by establishing a target level of safety. Following methodologies developed in civil aviation, the target level of safety is used to allocate appropriate integrity risk to each element of the system including localization. Next, we define the geometry of the problem to establish positioning bounds. This will be shown to be a function of road geometry standards such as lane widths and road curvature along with permissible vehicle dimensions. This analysis will focus on road and passenger vehicle standards in the United States, though the same principles can be applied to other regions and vehicle types.

In safety critical localization systems, the instantaneous estimate of the maximum possible error in position is known as the protection level. Figure 1 shows our definition of the lateral, longitudinal, and vertical protection levels around the vehicle. We define this as a box as this is a logical breakdown for road vehicles, though other forms based on ellipsoids have been proposed [21]. Some sensors and systems are better at providing lateral information such as cameras which can recognize lane lines and other types of sensors that can provide longitudinal information such as wheel odometry. The hard bounds on allowable lateral, longitudinal, and vertical protection levels are known as alert limits and are design choices which are dictated by geometry. We will choose these such that we always know we are within the lane. If our protection level is larger than our alert limit we cannot guarantee we are within the lane. Together, the desired integrity level and geometric bounds define the requirements of localization as a system.

Safety-critical localization systems specify their performance in terms of accuracy, integrity, and availability. Availability is a measure of how often our protection levels are larger than our alert limits. If we are always within the maximum permissible error (alert limits), we have 100\% availability. If we do so only some of the time, we have only limited availability. As a system, when operating in autonomous mode, localization must always be available. On the flip side, localization availability could be one of the metrics used to determine if the vehicle is within its Operational Design Domain to enable autonomous features. This could be a function of where high definition maps or other forms of supporting infrastructure are present.

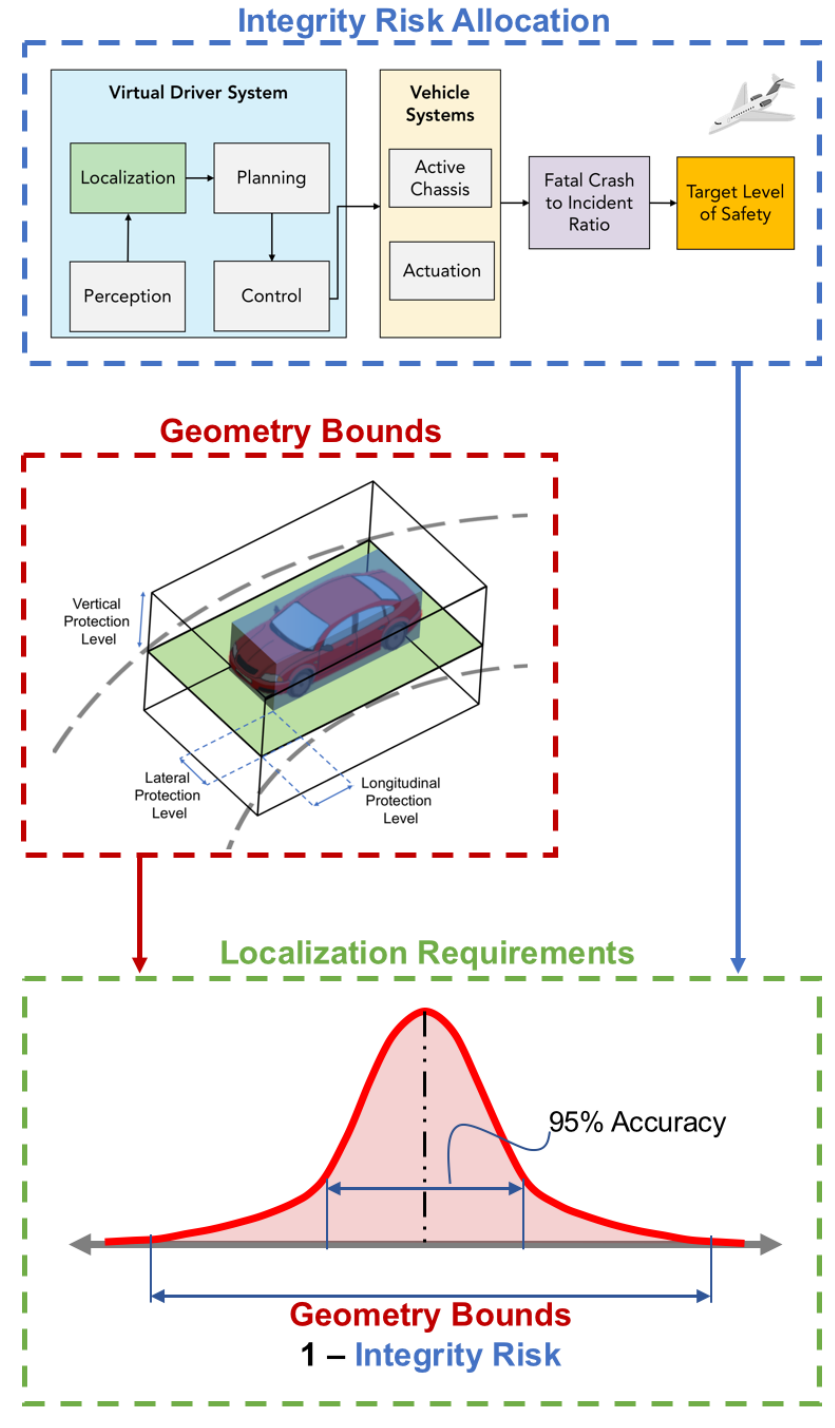

Fig. 4. Our approach to developing localization requirements for autonomous vehicles. We derive system integrity risk allocation based on a target level of safety. This risk budget is then distributed throughout the autonomous vehicle system, following methodologies developed in civil aviation. We define the geometry of the problem to establish positioning bounds based on vehicle dimensions and road geometry. Combining these defines the desired distribution of our position errors and the localization requirements.

Integrity describes how often our true error is outside of our estimate of maximum possible error or protection level. Outside of this and hazardous information is being fed to the vehicle's decision making and control systems. This is the probability of system failure, usually specified as probability of failure per hour of operation. We will derive the requirement on integrity based on the desired level of road safety. This will specify a level which represents improvement in road safety today by drawing comparisons to safety levels achieved in commercial aviation. We will also tie this integrity number to existing design safety standards in automotive and other industries. Figures 5 and 6 summarize the relationship between protection level, alert limit, availability, misleading information, and hazardous misleading information. These will 


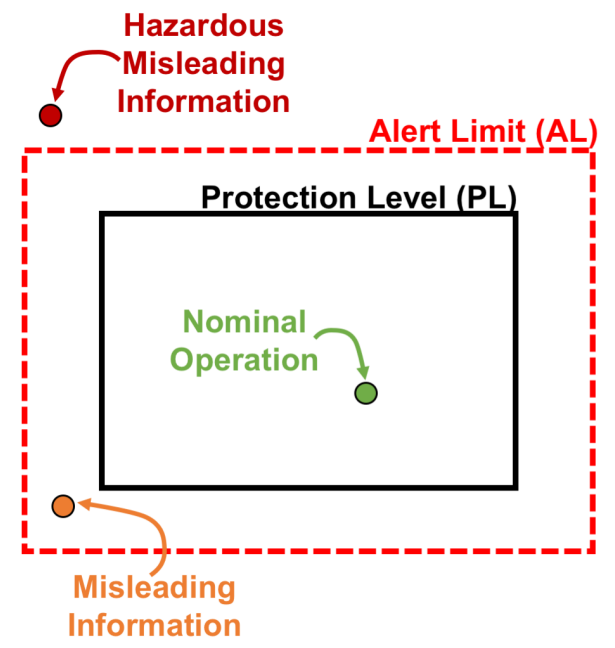

(a) Case I: $P L<A L$ along with examples of nominal, misleading, and hazardous misleading information.

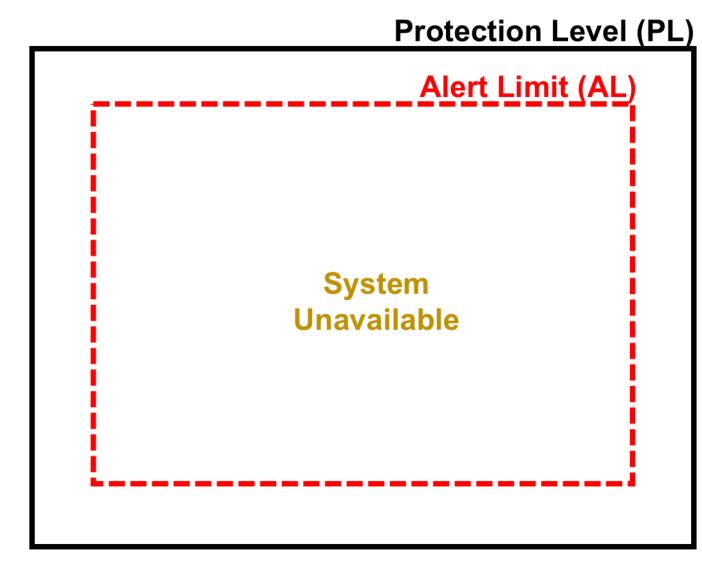

(b) Case II: $A L<P L$ resulting in no availability.

Fig. 5. Relationship between protection level, alert limit, availability, and different operations.

be developed in more detail throughout the text.

Accuracy is described by the typical performance of the system, usually measured at the 95th percentile. This is a manifestation of the desired statistical distribution of localization errors, where alert limits usually define the maximum allowable error for operation to the desired integrity level which define the tails of the statistical distribution. Hence, accuracy is a measure of nominal performance and integrity a measure of the limits. This relationship is shown in Figure 4

At present, there is no one localization technology that can meet the requirements presented here for safe operation in all weather, road, and traffic scenarios. Today, Ford Motor Company's autonomous vehicle research platform makes use of a complex sensor fusion strategy for localization and perception as shown in Figure 7. This includes LiDAR, radar, cameras, a Global Navigation Satellite System (GNSS) receiver, and an Inertial Measurement Unit (IMU). Each of these are a system in itself, and hence localization is a system of systems. Since no one technology can achieve the requirements in all scenarios, this will require multi-modal sensing and their

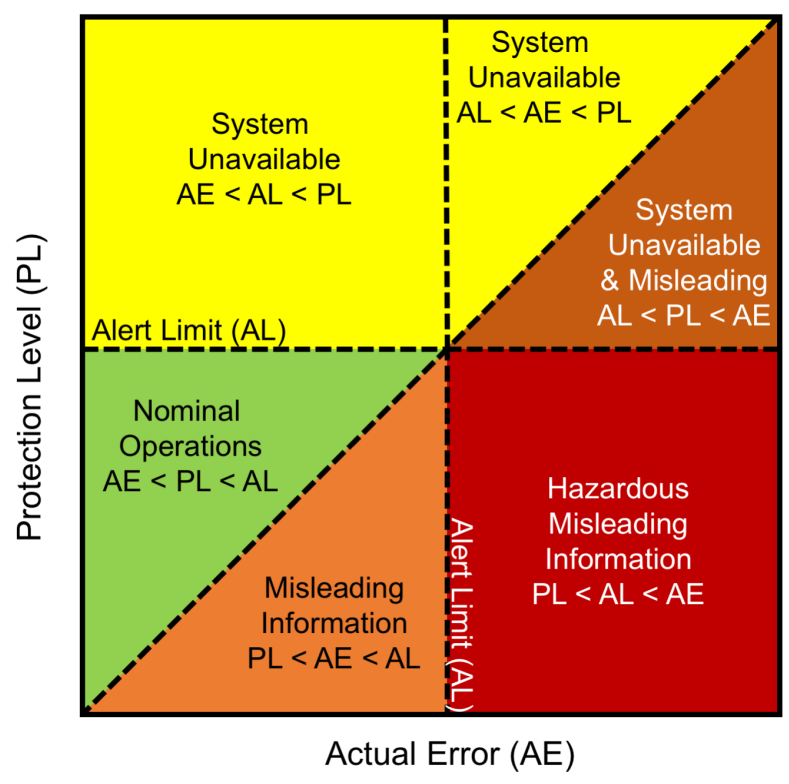

Fig. 6. The Stanford Diagram. This shows the relationship between actual error, protection level, and alert limit.

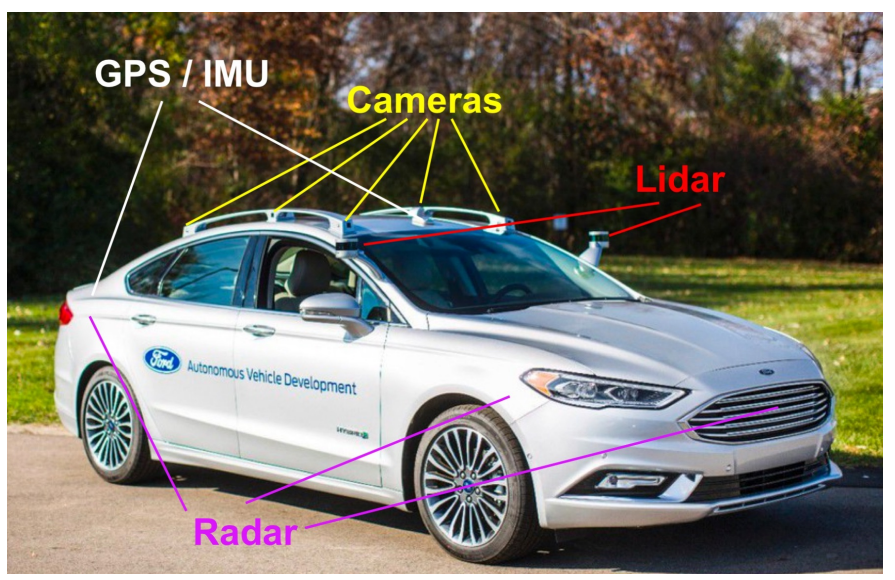

Fig. 7. Example of Ford's research autonomous vehicle platform sensors used in localization and perception.

intelligent combination to achieve the integrity levels needed for safe operation.

Though the sensor strategy shown in Figure 7 can meet many of the requirements that will be developed here in a research setting, the sensor costs are such that many challenges lie ahead on the path to production. Decimeter accuracy will require a trade-off between onboard sensors, compute resources / storage, and supporting infrastructure such as high definition maps and GNSS corrections. Such infrastructure may also limit where self-driving features are enabled due to availability of precise localization. Ultimately, precise vehicle location is only useful in context and hence a-priori maps are a major piece of the puzzle. We will limit the scope of this paper to localization requirements as mapping is a vast and complex area in its own right. We will touch on mapping requirements as they relate to localization. 


\section{INTEGRITY}

In 2016, there were 34,439 fatal car crashes in the United States, resulting in 37,461 fatalities [22], [23]. On a per mile basis, this is 1.18 fatalities per 100 million miles traveled $\left(1.18 \times 10^{-8}\right.$ fatalities / mile) [23]. The cause of vehicle crashes are estimated as follows: $94 \%( \pm 2.2 \%)$ from human driver errors; $2 \%( \pm 0.7 \%)$ from electrical and mechanical component failures; $2 \%( \pm 1.3 \%)$ from environmental factors contributing to slick (low $\mu$ ) roads such as water, ice, snow, etc.; and $2 \%( \pm 1.4 \%)$ from unknown reasons [24]. In total, road fatalities account for $95 \%$ of all transportation related fatalities in the United States where 2\% come from rail, $2 \%$ from water transport, and $1 \%$ from aviation [23]. Though the number of fatalities per road mile has decreased by five-fold since the 1960s, it has remained relatively constant over the last decade [23], [25].

Figure 8 compares fatalities on the road with commercial aviation on a per vehicle mile basis between $1960-2015$ in the US. This shows that between 2010 - 2015, commercial aviation averaged $2.50 \times 10^{-10}$ fatalities per mile, making air travel nearly two orders of magnitude safer than road travel when using this metric. Improvements in road safety are being proposed through automation, where sensors, silicon, and software are being combined into a virtual driver system which aims to perform many of the tasks of the human driver today. The first generation of commercially available virtual driver systems must be safer than the human drivers they aim to replace if they are to be socially accepted. Vehicle component failures are currently responsible for only $2 \%$ of crashes [24]. If this same metric is upheld for virtual driver systems which aim to replace the human factors representing $94 \%$ of crash causation today, then we strive to achieve roughly two orders of magnitude improvement in road safety. This brings the necessary system requirements for autonomous road vehicles up to the levels mandated in civil aviation, an industry known for its safety achieved through strict training for air and ground crew, supporting infrastructure, and well-developed standards.

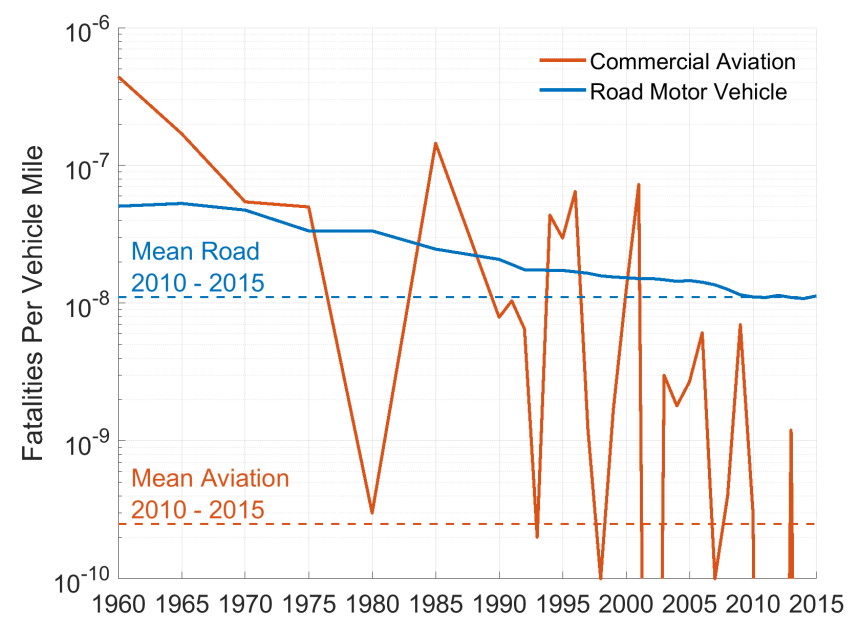

Fig. 8. Fatalities per vehicle mile 1960 - 2015 for road vehicles and commercial aviation in the US. Based on data from [23].

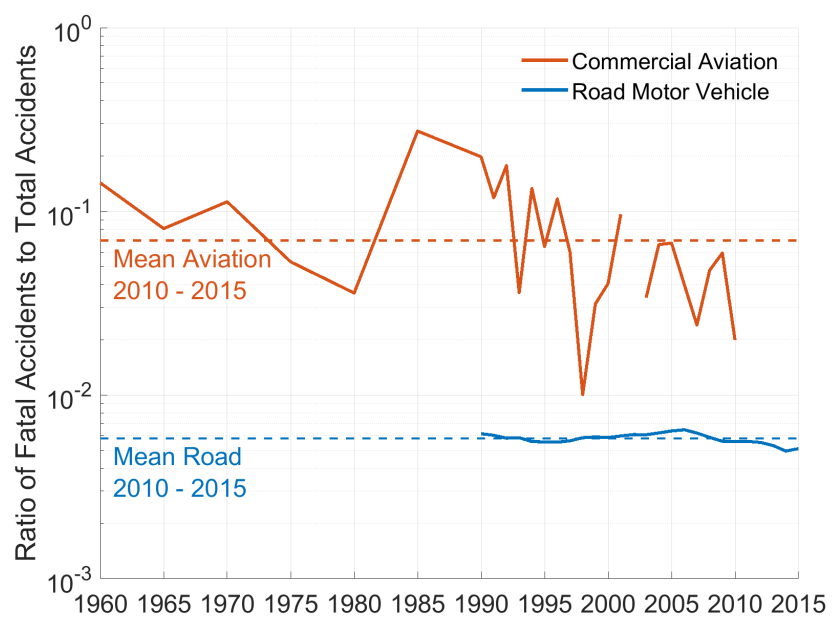

Fig. 9. Ratio of fatal accidents (crashes) to total reported accidents (crashes) between 1960 - 2015 for road vehicles and commercial aviation in the US. Based on data from [23] where data for road vehicles was only available from 1990 onward. In some recent years, commercial aviation saw no fatal accidents and hence the appearance of missing data.

Our starting point for this analysis will be the goal of a one hundred times improvement in road safety through the virtual driver system. This is the level of commercial aviation today at $2.50 \times 10^{-10}$ fatalities per mile and hence will be our target. To put this in units of fatal crashes per road vehicle mile, we must divide by the ratio of fatalities to fatal crashes which in 2016 was $37,461 / 34,439=1.09$ [23]. Being conservative, this leads to a target level of safety of $T L S=2 \times 10^{-10}$ fatal crashes per vehicle mile. To translate this into system level requirements, we must examine both historical data and the autonomous vehicle architecture, an approach mirroring that taken in civil aviation [26].

Figure 10 shows the system breakdown of the autonomous vehicle including the virtual driver and other vehicle modules. Furthermore, it shows one possible of allocation of integrity risk across individual elements with an end target level of safety of $T L S=2 \times 10^{-10}$ fatal crashes / vehicle mile. To arrive at this distribution, we must work backwards from the $T L S$. We must first account for the fact that not every malfunction will directly lead to a hazard that will cause a fatal crash. Some failures may only lead to a lane departure or minor crash. In aviation, this fatal accident to incident ratio $P_{F: I}$ is taken as 1:10 [27], [28], and Figure 9 shows why. This plot shows the yearly ratio of fatal to total reported accidents for commercial aviation and road transport. Aviation is shown to be $1: 14$ and automotive $1: 172$. This is not unexpected, due to the higher speed of operation of aircraft and consequently, the severity of crashes. Based on this historical data, we have conservatively chosen the automotive fatal crash to incident ratio as $P_{F: I}=$ $10^{-2}$ fatal crashes / failure, meaning one fatal crash for every one hundred incidents where an incident could be seen as a lane departure or minor crash.

Our chosen fatal crash to incident ratio is conservative, since this number represents the ratio of fatal crashes to all police reported crashes, not necessarily to all incidents. The 


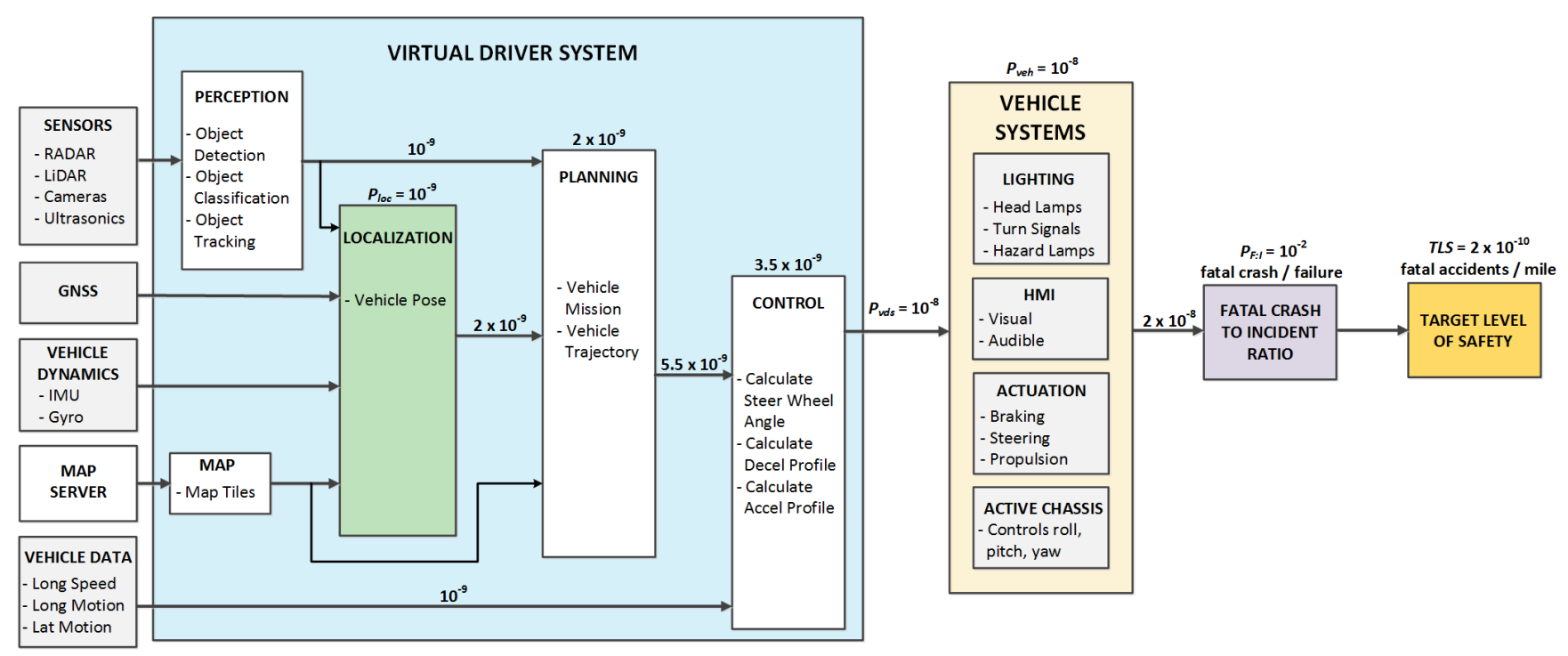

Fig. 10. Virtual driver system integrity risk allocation. Unless otherwise indicated, values are given as failures per mile. This diagram makes certain assumptions about how faults cascade through the system. For example, failures in localization output are assumed to lead directly to failures in planning though planning can also have its own independent failures as well. The target level of safety is derived based on numbers achieved in practice in aviation between 2010 2015. The fatal crash to incident ratio is based on historical road data from [23] (see Figure 9].

crash data in commercial aviation is generally reliable due to the strict reporting requirements. In automotive, this is less so, as not all minor crashes are reported. It is estimated that $60 \%$ of property-damage-only crashes and $24 \%$ of all injury crashes are not reported to the police [29]. Furthermore, the data supports that the 1 fatal crash for every 100 police reported crashes is consistent between functional road types, e.g. interstate and local urban roads, at least to within a factor of $2-3$ [30], [31]. Hence, we believe we are within an order of magnitude with this estimate for the majority of driving scenarios.

The next step is to allocate the acceptable level of integrity risk to vehicle systems $P_{v e h}$ and to the virtual driver system $P_{v d s}$. These are related to the target level of safety $T L S$ and fatal crash to incident ratio $P_{F: I}$ as follows:

$$
T L S=P_{F: I}\left(P_{v e h}+P_{v d s}\right)
$$

To reach our $T L S=2 \times 10^{-10}$ fatal crashes / vehicle mile, we will allocate equal integrity risk to both the virtual driver and vehicle systems. This works out to $P_{v d s}=P_{v e h}=$ $10^{-8}$ failures / mile and is reflected in Figure 10. For clarity, plugging in these values into equation (1) gives the desired result:

$$
\begin{aligned}
T L S & =P_{F: I}\left(P_{v e h}+P_{v d s}\right) \\
& =10^{-2} \frac{\text { fatal crashes }}{\text { failure }}\left(10^{-8}+10^{-8}\right) \frac{\text { failure }}{\text { mile }} \\
& =2 \times 10^{-10} \text { fatal crashes } / \text { mile }
\end{aligned}
$$

Examination of historical data reveals that vehicle system failure rates $P_{v e h}$ are very nearly $10^{-8}$ failures / mile today. This can be estimated through police reported crashes, NHTSA estimates of crash causation due to vehicle systems, and the number of vehicle miles driven. On average, between 2010 - 2015 there was 5,800,000 police reported crashes per year on US roads [23]. These crashes are the rounded sum of fatal crashes, an actual count from the Fatality Analysis Reporting System, injury crashes, and property damage only crashes, which are estimates from the National Automotive Sampling System-General Estimates System [23]. Currently, NHTSA estimates $2 \%( \pm 0.7 \%)$ of these crashes to be caused by vehicle systems [24]. Using this, along with the fact that $3,005,829,000,000$ miles were driven on average in the US between 2010 - 2015, we can obtain an estimate of historical failure rate $\hat{P}_{v e h}$ :

$$
\begin{aligned}
\hat{P}_{\text {veh }} & =\frac{5,800,000 \text { crashes }}{3,005,829,000,000 \text { miles }} \times 2 \% \\
& =3.8 \times 10^{-8} \text { failures } / \text { mile }
\end{aligned}
$$

Though there are sources of uncertainty in each of the values used above, this shows that vehicle systems are at the proposed order of magnitude, indicating that $10^{-8}$ failures / mile can likely be attained if it is not already.

Achieving the desired integrity risk for the virtual driver system $P_{v d s}$ will require a closer look at its subsystems. In our case, we are focused on localization. Localization will need to have a lower probability of failure since it feeds other elements of the virtual driver system. This includes hardware and software failures within perception, localization, planning, and control. Figure 10 shows the internal elements of the virtual driver system and the importance of localization within the system. The output of localization is an input to planning, and the output of planning is the input to control, therefore failures in localization propagate downstream. One possible allocation of integrity risk to all virtual driver subsystems is shown in Figure 10 where localization is targeted at $P_{l o c}=$ $10^{-9}$ failures / mile. This diagram assumes that failures at any given point downstream are a combination of upstream input failures along with failures of the given subsystem. $P_{l o c}$ is typically referred to as the probability of the localization 
TABLE II

LOCALIZATION REQUIREMENTS FOR MARITIME, AVIATION, AND RAIL.

\begin{tabular}{|c|c|c|c|c|}
\hline Transport Mode & Operation & $\begin{array}{c}\text { Accuracy } \\
(95 \%) \\
{[\mathrm{m}]}\end{array}$ & $\begin{array}{c}\text { Alert } \\
\text { Limit } \\
{[\mathrm{m}]}\end{array}$ & $\begin{array}{l}\text { Probability } \\
\text { of Failure }\end{array}$ \\
\hline \multirow{2}{*}{ Maritime 33 } & $\begin{array}{l}\text { Open Ocean, } \\
\text { Coastal }\end{array}$ & $10^{* *}$ & $25^{* *}$ & $10^{-5} / 3 \mathrm{~h}$ \\
\hline & $\begin{array}{l}\text { Port, } \\
\text { Hydrography, } \\
\text { Drilling }\end{array}$ & $1^{* *}$ & $2.5^{* *}$ & $10^{-5} / 3 \mathrm{~h}$ \\
\hline \multirow[b]{2}{*}{ Aviation [28, 34] } & $\begin{array}{l}\text { LPV } 200 \text { Air- } \\
\text { port Approach }\end{array}$ & $4^{*}$ & $35^{*}$ & $10^{-7} / 150 \mathrm{~s}$ \\
\hline & $\begin{array}{l}\text { CAT II / III } \\
\text { Instrument } \\
\text { Landing }\end{array}$ & $2.9^{*}$ & $5^{*}$ & $10^{-9} / 150 \mathrm{~s}$ \\
\hline \multirow[b]{2}{*}{ Rail 35 } & Train control & - & $20^{* *}$ & $10^{-9} / \mathrm{h}$ \\
\hline & $\begin{array}{l}\text { Parallel track } \\
\text { discrimination }\end{array}$ & - & $2.5^{* *}$ & $10^{-9} / \mathrm{h}$ \\
\hline
\end{tabular}

*Vertical

**Horizontal

system outputting hazardous misleading information (as described in Section [1]. To get this in terms of failures per hour of operation (a more common unit), we first need to determine the vehicle speed range. Maximum speed limits in the US are found in Texas at $85 \mathrm{mph}(137 \mathrm{~km} / \mathrm{h})$. On the lower side, we will consider the minimum speed at which airbags will deploy, which corresponds to $10 \mathrm{mph}(16 \mathrm{~km} / \mathrm{h})$ [32]. These speeds give the following range:

$$
\begin{aligned}
P_{l o c} & =10^{-9} \frac{\text { failures }}{\text { mile }} \times(10-85) \frac{\text { mile }}{\text { hour }} \\
& \approx 10^{-8} \frac{\text { failures }}{\text { hour }}
\end{aligned}
$$

In this analysis of the localization system, we will examine an allowable integrity risk of $10^{-8}$ failures / hour of operation. This is the requirement on the localization system as a whole, which itself may be comprised of several subsystems, sensors, and independent localization algorithms based on GNSS, IMU, cameras, LiDAR, maps, and other elements. This is the number that must be achieved in all weather and traffic scenarios where the vehicle intends operation. The gold standard from ISO 26262 for automotive functional safety is 10 Failures In Time (FIT) which corresponds to 10 failures in one billion hours of operation or $10^{-8}$ failures / hour of operation. This aligns with our intended target. This is Automotive Safety Integrity Level (ASIL) D, the highest standard for current automobiles. Though the error distribution of the localization system may not be Gaussian, when thinking of this in Gaussian terms, $\left(1-10^{-8}\right)$ is $99.999999 \%$ or approximately $5.73 \sigma$.

The localization requirements in maritime [33], aviation [27], [28], [34], and rail [35], [36] for specific operations are given in Table $\Pi$ for comparison. Here, we specify the $95 \%$ localization accuracy, the alert limit which is the hard bound on position error to ensure safe operation, and the acceptable probability of system failure or integrity risk. In aviation, the operations given correspond to airport precision approach
TABLE III

TYPICAL CHARACTERIZATION OF SAFETY RISK BASED ON DATA FROM [38]-42].

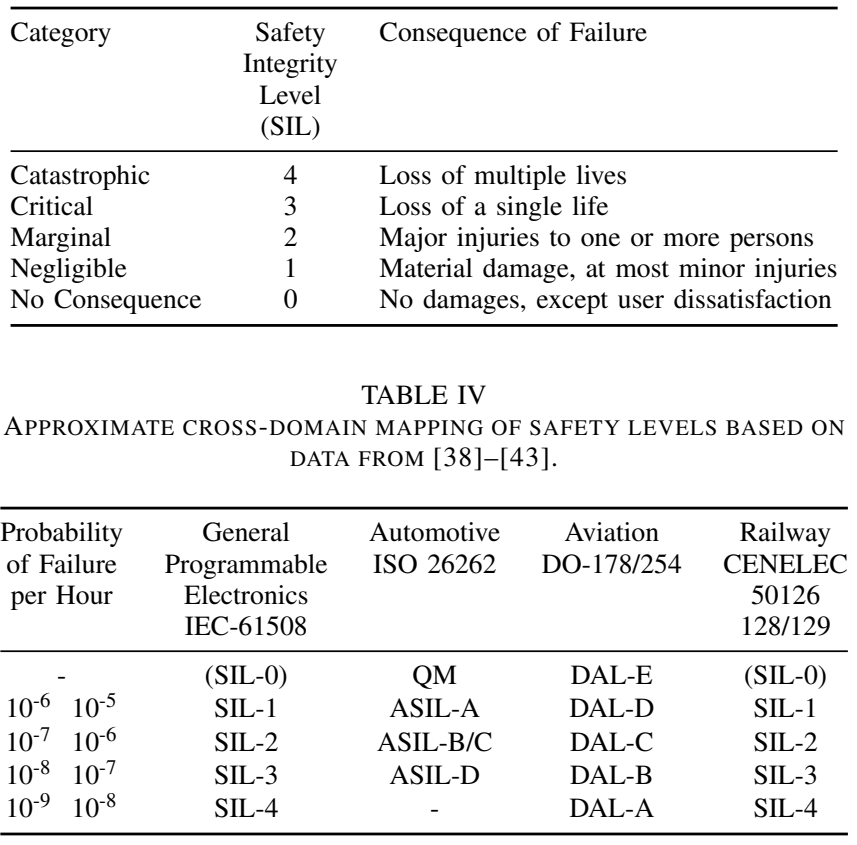

and landing. The timescale associated with probability of failure of 150 seconds corresponds to the typical time this operation takes. Localizer Performance with Vertical guidance (LPV 200) gets the aircraft down to a decision height of 200 feet $(61 \mathrm{~m})$ above the runway where the pilot can decide to either land the aircraft or fly around and make another approach. CAT II / III is full instrument landing and hence the two orders of magnitude difference in acceptable failure rate since the system is fully automated. Maritime operations happen at lower speeds and is why integrity is specified over 3 hours. However, it can be shown that $10^{-5}$ failures per 3 hours is roughly equivalent to aircraft precision approach requirements at $10^{-7}$ failures per 150 seconds [37]. Rail has separate along-track and cross-track requirements. Along-track requirements describe where trains are along a given track known as train control. Cross-track requirements are needed to distinguish which track the train is on known as parallel track discrimination. Track discrimination requirements are most strict since the inter-track spacing is tighter than the spacing kept between trains on the same line. Both rail operations require a failure rate of $10^{-9}$ failures / hour of operation. For the virtual driver localization system, we are aiming for $10^{-8}$ failures / hour or better since the virtual driver system itself will be designed to ASIL-D standards. Though this target integrity level has precedence in other transportation industries, the required alert limits do not. We will show in the coming sections that alert limits needed for road vehicles is on the order of decimeters, an order of magnitude smaller than anything in Table $\mathrm{II}$.

To put probability of failure per hour of operation in context, we will compare it to safety standards across different industries. Table III shows the typical breakdown of Safety Integrity Level (SIL) by hazard category. The strictest 
level (SIL-4) occurs where the consequence of failure is the loss of multiple human lives. The more lenient level, SIL-0, represent cases where the consequence of failure is only some dissatisfaction or discomfort. Table IV shows an approximate cross-domain mapping of aviation, rail, general programmable electronics, and automotive safety integrity levels. In rail, aviation, and programmable electronics, the strictest levels are those corresponding to failures which could cause the loss of multiple human lives and correspond to an integrity level of $10^{-9}$ failures / hour. In rail and electronics this is SIL-4. In aviation, this is Design Assurance Level (DAL) A. The automotive industry's strictest requirement, Automotive Safety Integrity Level (ASIL) D is closer to SIL-3 and DAL-B in practice or $10^{-8}-10^{-7}$ failures / hour [43]. We're targeting $10^{-8}$ failures / hour for the localization system, putting us in the range of ASIL-D. The virtual driver system will also be designed to ASIL-D standards, and hence it follows that subsystems like localization need to comply with this standard.

\section{HORIZONTAL REQUIREMENTS}

The horizontal localization requirements for autonomous vehicles are a function of their physical dimensions and the road geometry. The goal is to keep the vehicle in its respective lane during typical operation. This leads to lateral and longitudinal localization requirements as shown in Figure 11a. To scale, this shows the lateral clearance that can be expected with a mid-size sedan (e.g. a Ford Fusion) on a straight stretch of US freeway. This makes it appear as though lateral and longitudinal requirements are decoupled, but this is not entirely the case. Figure $11 \mathrm{~b}$ shows the coupling between these directions in turns, hence road curvature causes coupling between requirements in lateral and longitudinal directions. The analysis presented here will be focused on standards within the United States where assumptions will be made about typical vehicle width $w_{v}$, vehicle length $l_{v}$, road width $w$, and road radius of curvature $r$. A similar analysis could be undertaken with road and vehicle standards of other regions.

TABLE V

VEHICLE DIMENSION STANDARDS IN THE US [44], [45].

\begin{tabular}{lccc}
\hline Vehicle Type & Width [m] & Length [m] & Height [m] \\
\hline Passenger (P) & 2.1 & 5.8 & 1.3 \\
Single Unit Truck (SU) & 2.4 & 9.2 & $3.4-4.1$ \\
City Bus & 2.6 & 12.2 & 3.2 \\
Semitrailer & $2.4-2.6$ & $13.9-22.4$ & 4.1 \\
\hline
\end{tabular}

We will begin with vehicle dimensions. Standards for road vehicle dimensions in the US are summarized in Table V and reflect maximum dimensions for different vehicle classes. A more detailed breakdown for some example passenger (P) vehicles is given in Table VI This ranges from the subcompact to large 6-wheel 'dualie' pickup trucks though the latter technically falls into the single unit truck (SU) category. As will be discussed, not all vehicles are meant for all roads, and hence some care must be taken when developing the localization requirements for vehicles. For example, semitrucks are not meant to be driven on residential streets and

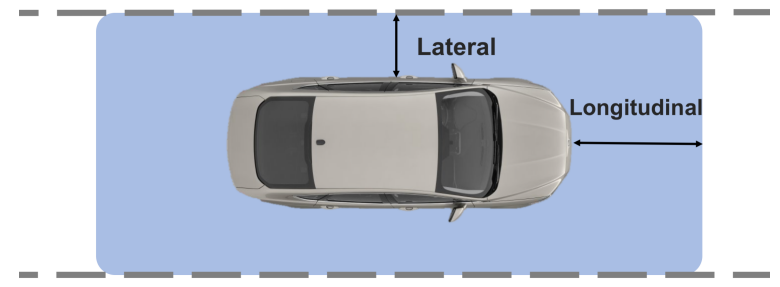

(a) Straight road.

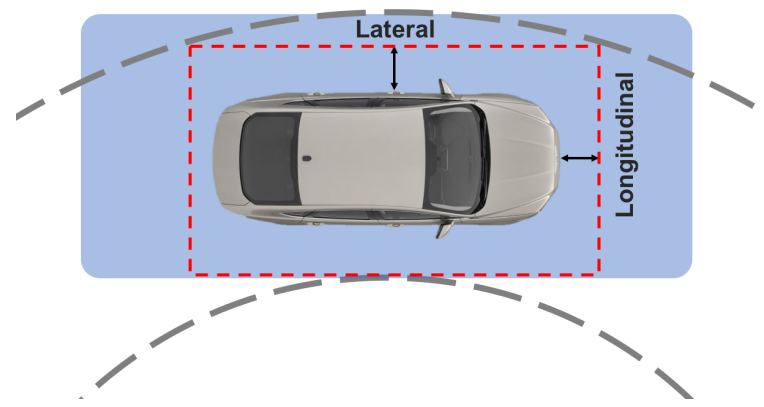

(b) Curved road.

Fig. 11. Bounding box required for localization broken down by lateral and longitudinal components.

TABLE VI

TYPICAL VEHICLE DIMENSIONS

\begin{tabular}{llccc}
\hline Vehicle Type & Example $^{*}$ & Width [m] & Length $[\mathrm{m}]$ & Height $[\mathrm{m}]$ \\
\hline Subcompact & Fiesta & 1.72 & 4.06 & 1.48 \\
Compact & Focus & 1.82 & 4.54 & 1.47 \\
Mid-Size & Fusion & 1.85 & 4.87 & 1.48 \\
Full-Size & Taurus & 1.94 & 5.15 & 1.54 \\
Crossover & Escape & 1.84 & 4.52 & 1.68 \\
Small SUV & Edge & 1.93 & 4.78 & 1.74 \\
Standard SUV & Explorer & 2.00 & 5.04 & 1.78 \\
Van & Transit & $2.07-2.13^{* *}$ & $5.59-6.70^{* *}$ & $2.09-2.76^{* *}$ \\
Pickup Truck & F-series & $2.03-2.43^{* *}$ & $5.32-6.76^{* *}$ & 2.06 \\
\hline
\end{tabular}

*Based on 2018 Ford model year.

**The wider F-series trucks \& Transits are dual wheeled or 'dualies.'

hence requirements should not be set to roadways that are impossible for such a vehicle to navigate. Here, we will focus on passenger vehicles.

Next is road geometry. Road curvature is a function of design speed and is based on limiting values of side friction factor $f$ and superelevation $e$ [44]. Superelevation is the rotation of the pavement on the approach to and throughout a horizontal curve and is intended to help the driver by countering the lateral acceleration produced by tracking the curve. The other important factor is road width, which typically ranges from 3.6 meters on standard freeways to 2.7 meters on limited residential streets [44]. Road width and curvature are the elements that define the localization requirements to ensure the vehicle knows it is within its lane to the certainty level defined in Section III The limiting cases for each road type have been assembled in Table VII for passenger type (P) 
TABLE VII

SOME LIMITING ROAD DESIGN ELEMENTS, BASED ON DESIGNS FOR PASSENGER (P) VEHICLES. BASED ON DATA FROM [44], [46], [47].

\begin{tabular}{lccc}
\hline Road Type & $\begin{array}{c}\text { Design } \\
\text { Speed } \\
{[\mathrm{km} / \mathrm{h}]}\end{array}$ & $\begin{array}{c}\text { Lane Width } \\
{[\mathrm{m}]}\end{array}$ & $\begin{array}{c}\text { Minimum } \\
\text { Radius }[\mathrm{m}]\end{array}$ \\
\hline Freeway & $80-130$ & 3.6 & $195^{* *}$ \\
Interchanges & $30-110$ & $3.6-5.4$ & $150-15$ \\
Arterial & $50-100$ & $3.3-3.6$ & $70^{* *}$ \\
Collector & 50 & $3.0-3.6$ & $70^{* *}$ \\
Local & $20-50$ & $2.7^{*}-3.6$ & $10^{* *}$ \\
$\begin{array}{l}\text { Hairpin Turn / } \\
\text { Cul-de-Sac }\end{array}$ & $<20$ & 6.0 & 7 \\
$\begin{array}{l}\text { Single Lane } \\
\text { Roundabout }\end{array}$ & $<20$ & 4.3 & 11 \\
\hline
\end{tabular}

*The lower bound of $2.7 \mathrm{~m}$ is the exception, not the rule, and is typically reserved for residential streets with low traffic volumes.

**Based on design speeds and limiting values of rate of roadway superelevation $e$ and coefficient of friction $f$.

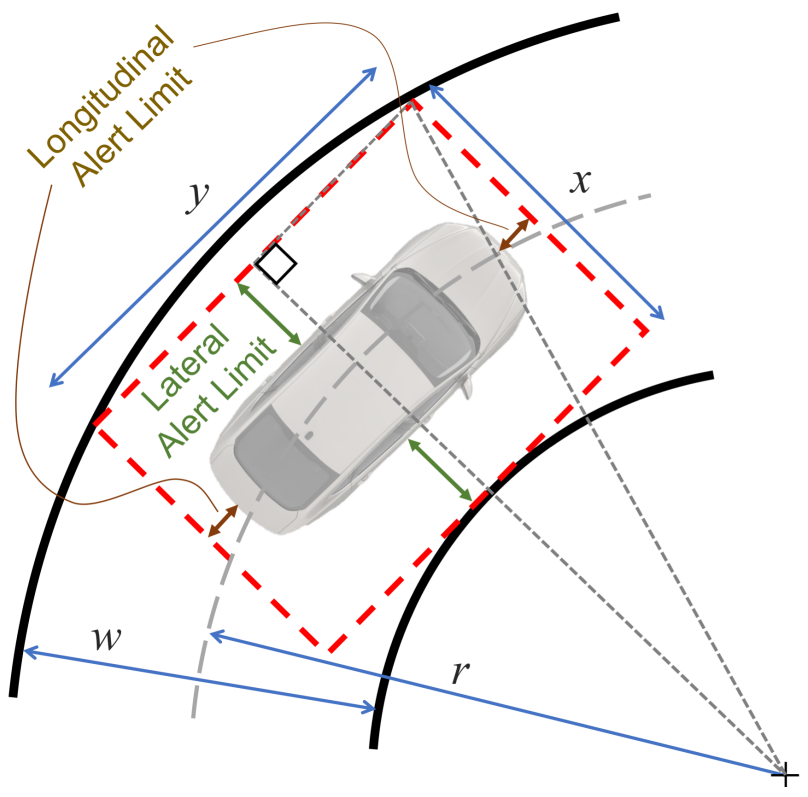

Fig. 12. Bounding box geometry in a turn. This shows the allowable maximum position error of the vehicle to ensure it is within the lane known as the alert limits.

vehicles.

The relationship between the road width and curvature and the interior bounding box around the vehicle is shown in Figure 12. The relationship between the lateral and longitudinal bounds is found by Pythagoras:

$$
\left(\frac{y}{2}\right)^{2}+\left(r-\frac{w}{2}+x\right)^{2}=\left(r+\frac{w}{2}\right)^{2}
$$

Solving for $x$ results in:

$$
x=\sqrt{\left(r+\frac{w}{2}\right)^{2}-\left(\frac{y}{2}\right)^{2}}+\frac{w}{2}-r
$$

This allows us to determine the dimensions of the bounding box given the road geometry. In turn, given the vehicle

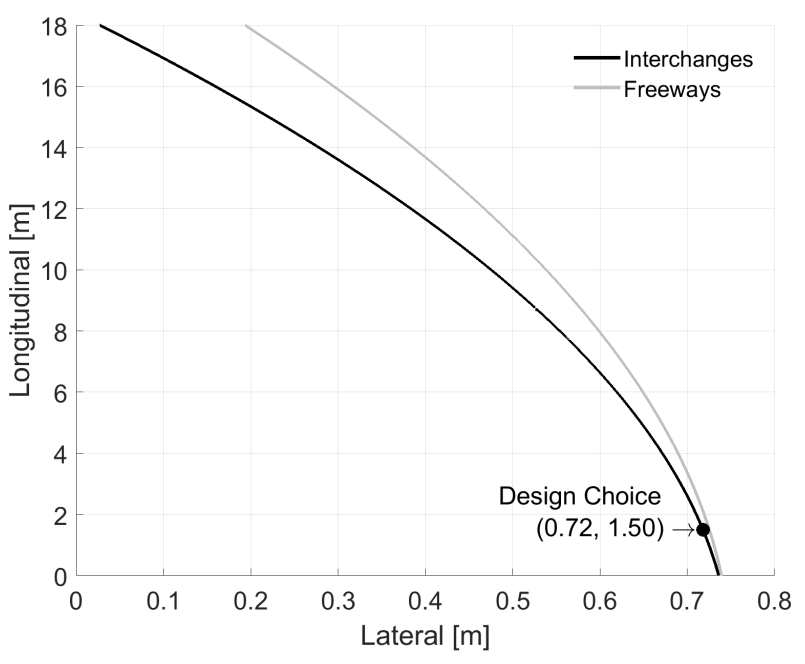

Fig. 13. Lateral and longitudinal alert limit trade off for freeway and interchange geometry and passenger vehicle dimension limits. This is limited by lane widths of 3.6 meters with a minimum curvature of 150 meters.

dimensions, corresponding maximum permissible lateral and longitudinal errors (alert limits) can be derived. Lateral and longitudinal alert limits are a trade-off and there is a certain budget between them which is dependent on the road type. The lateral localization requirements are coupled to longitudinal through the allowed curvature and width of the road. For example, on the highway at high speed, the allowable road curvature is minimal and roads are fairly straight. This allows for the bounding box length to be large longitudinally before lateral requirements are overly constrained. Ultimately, choosing length $y$ fixes width $x$ or vice versa, and the resulting lateral and longitudinal alert limits are related to the vehicle length $l_{v}$ and width $w_{v}$ as follows:

$$
\begin{aligned}
\text { Lateral Alert Limit } & =\left(x-w_{v}\right) / 2 \\
\text { Longitudinal Alert Limit } & =\left(y-l_{v}\right) / 2
\end{aligned}
$$

Using equations (6) and (7), the trade-off between lateral and longitudinal alert limits for freeways assuming passenger vehicle design limits is shown in Figure 13 . This shows that as the longitudinal requirements are relaxed to several meters, the lateral requirements become more stringent. However, ultimately on/off ramps must be found within a reasonable tolerance on the freeway, so there is a more stringent longitudinal requirement based on vehicle operation. This is also constrained by situations where vehicles may be operating collaboratively and sharing their location via communications channels (V2X) [21]. In this design study, we limit the longitudinal alert limit to be less than half the length of a subcompact vehicle or 1.5 meters, well within the limits of reasonable highway following distances (even with the combined errors of two vehicles operating collaboratively) and the vehicle's ability to appropriately find on/off-ramps. With this longitudinal design number, we use Figure 13 to determine the required lateral alert limit to be 0.72 meters. The lateral alert limit for other vehicle types is summarized in Table VIII

On the highway, lateral dominates the requirements since the coupling with curvature is negligible and is approximately 


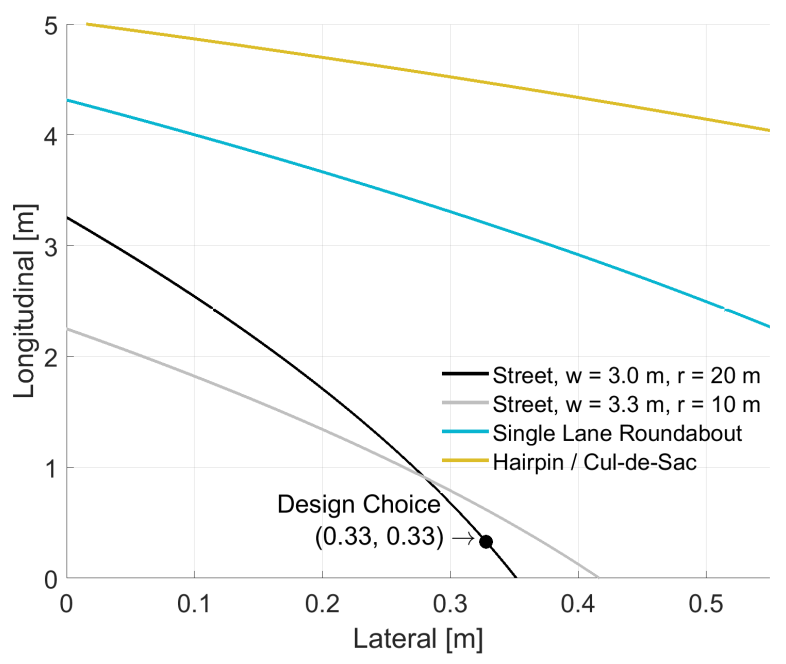

Fig. 14. Lateral and longitudinal alert limit trade off for local road geometry and passenger vehicle dimension limits. Narrow streets are assumed to be 3.0 meters wide with a minimum curvature of 20 meters or 3.3 meters wide with minimum curvature of 10 meters. Single lane roundabouts and hairpin / cul-de-sac geometry is included for comparison.

1 centimeter over the length of the largest pickup trucks. Hence, on the highway, the longitudinal alert limit is to some extent a design parameter. On local streets, with sharp turns, the curvature coupling results in tighter requirements in both directions. Figure 14 shows the trade-off between lateral and longitudinal alert limits for local road geometry for passenger vehicle limits. In this plot, we restrict the analysis to roads 3.3 meters wide with a curvature of 10 meters and 3.0 meters wide with a curvature of 20 meters. Also shown are the results for single lane roundabouts and hairpin turns. Though Table VII shows that some roads can be as narrow as 2.7 meters, this is the exception not the rule and we felt it too restricting to limit requirements based on this number. In addition, roads with tight curvature usually have wider lanes to accommodate as shown by the design recommendations for single lane roundabouts and hairpin turns / cul-de-sacs. Hence, these requirements are still conservative when neglecting 2.7 meters wide lanes [47].

For local streets, Figure 14 shows the trade-off between lateral and longitudinal alert limits. Thinking of limiting cases where vehicles are negotiating 90 degree turns, it seems logical that both directions become equally important to properly complete the maneuver, so the alert limits should be balanced equally in both directions. Figure 14 shows the equality point to be 0.33 meters for both the lateral and longitudinal alert limits for the largest passenger vehicles. Other vehicle types are summarized in Table VIII For scale, when operating in urban environments, 0.33 meters is also the minimum width of stop lines which are mandated to be between 0.3 and 0.6 meters (12 - 24 inches) [48].

\section{Vertical ReQuirements}

The recommended minimum vertical clearance for roads in the US is 4.4 meters (14.5 feet) [25]. This standard drives the permissible vertical height, including load, to be between

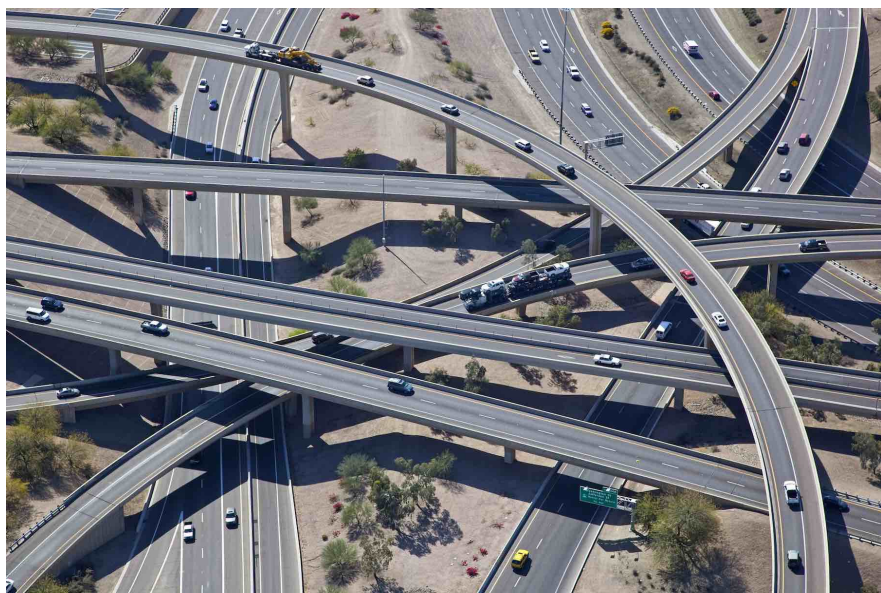

Fig. 15. Example of a multi-level interchange in Phoenix, AZ. The 'Mini Stack' is at the intersection of Interstate 10, State Route 51, and Loop 202.

4.1 meters (13.5 feet) and 4.3 meters (14.5 feet), though this varies somewhat by state [44], [45]. Hence to reliably determine which road level we are on of an interchange for example, we must know our position to a fraction of this clearance height. Bounding our vertical position to \pm half of this clearance is insufficient since this leaves a potential ambiguity on multi-decked roads or interchanges. An example of such an interchange is the 'Mini Stack' in Phoenix, Arizona shown in Figure 15. This multi-level interchange is at the intersection of Interstate 10, State Route 51, and Loop 202. For certainty, one-third of the minimum vertical clearance should be sufficient to resolve the ambiguity of which road level the vehicle is on. Hence the required Vertical Alert Limit (VAL) is:

$$
\mathrm{VAL}=\frac{\text { min. vertical clearance }}{3}=\frac{4.4 \mathrm{~m}}{3}=1.47 \mathrm{~m}
$$

Here, the vertical alert limit is vehicle independent (i.e. not dependent on vehicle dimensions) since it is used only to determine the road level. This differs from horizontal requirements developed in Section III which strive to maintain a vehicle of certain dimensions within the bounds of the lane. This is reflected in Table VIII which summarizes the lateral, longitudinal, and vertical alert limits for several vehicle types and different road operations including freeways / interchanges and local roads.

It should be noted that this vertical positioning analysis has some limitations. As this analysis is seen as the far reaching goal for highly automated systems, the assumption here is that the vehicle will have a form of map to help in resolving position. In the interim, other applications such as V2X will likely not have maps. In the V2X scenario, the limiting factor for the vertical requirement is the trajectory estimation to determine whether or not a principal other vehicle is on a collision path with the subject vehicle. That is, elevation error will make a grade-separate interaction appear to be an atgrade crossing with collision potential. This is a more complex analysis to perform which is outside the scope of this paper. 
TABLE VIII

HORIZONTAL (LATERAL / LONGITUDINAL) AND VERTICAL LOCALIZATION ALERT LIMIT REQUIREMENTS FOR US FREEWAYS AND LOCAL ROADS.

\begin{tabular}{l|ccc|ccc}
\hline \multirow{2}{*}{ Vehicle Type } & \multicolumn{3}{|c|}{ Local Roads } & \multicolumn{3}{c}{ Freeways \& Interchanges } \\
& $\begin{array}{r}\text { Lat. } \\
{[\mathrm{m}]}\end{array}$ & $\begin{array}{c}\text { Long. } \\
{[\mathrm{m}]}\end{array}$ & $\begin{array}{c}\text { Vert. } \\
{[\mathrm{m}]}\end{array}$ & $\begin{array}{c}\text { Lat. } \\
{[\mathrm{m}]}\end{array}$ & $\begin{array}{c}\text { Long. } \\
{[\mathrm{m}]}\end{array}$ & $\begin{array}{c}\text { Vert. } \\
{[\mathrm{m}]}\end{array}$ \\
\hline Mid-Size & 0.48 & 0.48 & 1.47 & 0.85 & 1.50 & 1.47 \\
Full-Size & 0.42 & 0.42 & 1.47 & 0.80 & 1.50 & 1.47 \\
Standard Pickup & 0.38 & 0.38 & 1.47 & 0.76 & 1.50 & 1.47 \\
$\begin{array}{l}\text { Passenger Vehicle } \\
\text { Limits }\end{array}$ & 0.33 & 0.33 & 1.47 & 0.72 & 1.50 & 1.47 \\
6-Wheel Pickup & - & - & - & 0.56 & 1.50 & 1.47 \\
\hline
\end{tabular}

\section{ORIENTATION REQUiREMENTS}

The horizontal and vertical alert limits discussed so far are the acceptable limit for all combined sources of error. As will be discussed in this section, this will include errors in both positioning and attitude (orientation). The vehicle attitude is described in terms of its roll $\theta$, pitch $\phi$, and heading $\psi$ angles. Errors in these parameters will rotate the position protection level box around the vehicle and result in a larger effective protection level. This effect is shown in Figure 16 This shows how errors in heading and position map to a larger combined protection level area and hence why knowledge of attitude error is important.

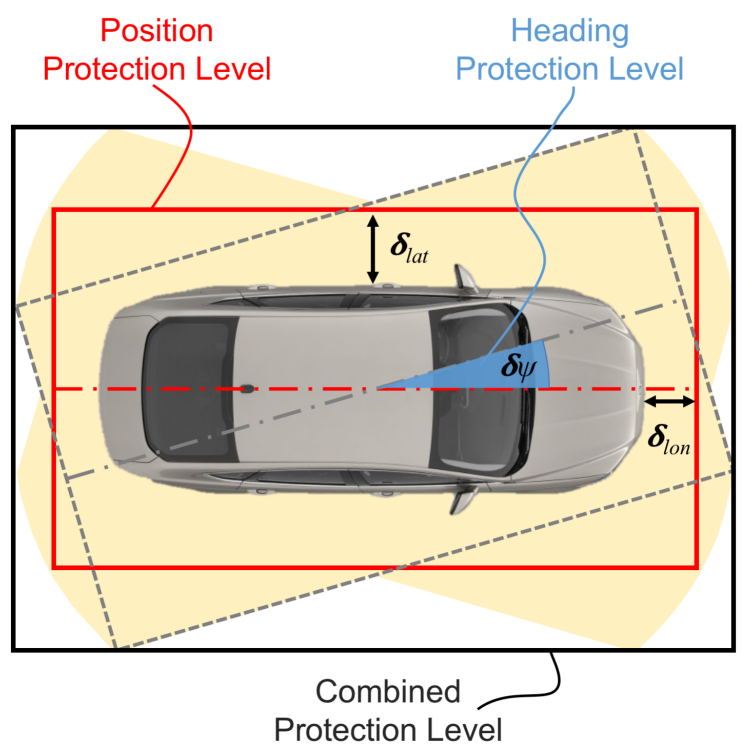

Fig. 16. Combined effect of lateral / longitudinal position and heading errors on overall protection level. Heading errors rotate position errors and lead to a larger effective area of uncertainty.

This effect leads to requirements on acceptable errors in roll, pitch, and heading as well as position. We will begin with mapping errors in position and orientation into a combined protection level. Assuming a box around the vehicle of width $x$, length $y$, and height $z$ (following the notation of Figure 12), maximum errors in roll $\pm \delta \theta$, pitch $\pm \delta \phi$, and heading $\pm \delta \psi$ angles are mapped through the following Euler sequence:

$$
\mathbf{x}^{\prime}=\mathbf{R}_{3}( \pm \delta \psi) \mathbf{R}_{2}( \pm \delta \theta) \mathbf{R}_{3}( \pm \delta \phi) \mathbf{x}
$$

where $\mathbf{x}$ is the dimensions of the box $[x, y, z]^{T}$ reflecting position protection level, $\mathbf{x}^{\prime}$ is the dimensions of the inflated box $\left[x^{\prime}, y^{\prime}, z^{\prime}\right]^{T}$ representing the protection level from both positioning and orientation, and $\mathbf{R}_{i}$ are the following rotation matrices:

$$
\begin{aligned}
& \mathbf{R}_{1}( \pm \delta \phi)=\left[\begin{array}{ccc}
1 & 0 & 0 \\
0 & \cos ( \pm \delta \phi) & -\sin ( \pm \delta \phi) \\
0 & \sin ( \pm \delta \phi) & \cos ( \pm \delta \phi)
\end{array}\right] \\
& \mathbf{R}_{2}( \pm \delta \theta)=\left[\begin{array}{ccc}
\cos ( \pm \delta \theta) & 0 & \sin ( \pm \delta \theta) \\
0 & 1 & 0 \\
-\sin ( \pm \delta \theta) & 0 & \cos ( \pm \delta \theta)
\end{array}\right] \\
& \mathbf{R}_{3}( \pm \delta \psi)=\left[\begin{array}{ccc}
\cos ( \pm \delta \psi) & -\sin ( \pm \delta \psi) & 0 \\
\sin ( \pm \delta \psi) & \cos ( \pm \delta \psi) & 0 \\
0 & 0 & 1
\end{array}\right]
\end{aligned}
$$

The position protection level $\mathbf{x}$ is related to errors in lateral $\delta_{l a t}$, longitudinal $\delta_{l o n}$, and vertical $\delta_{\text {vert }}$ positioning as follow:

$$
\mathbf{x}=\left[\begin{array}{c}
x \\
y \\
z
\end{array}\right]=\left[\begin{array}{c}
w_{v}+2 \delta_{\text {lat }} \\
l_{v}+2 \delta_{\text {lon }} \\
2 \delta_{\text {vert }}
\end{array}\right]
$$

We are after the worst-case error bounds, which are obtained by letting all the terms constructively add by setting $\cos ( \pm \delta \cdot) \rightarrow \cos (\delta \cdot)$ and $\pm \sin ( \pm \delta \cdot) \rightarrow \sin (\delta \cdot)$. By necessity, errors in orientation will also have to be small, meaning $\delta \theta$, $\delta \phi$, and $\delta \psi$ will be $\ll 1$ radian (57 degrees). This allows us to make a small angle approximation to simplify these equations, where $\cos (\delta \cdot) \rightarrow 1$ and $\sin (\delta \cdot) \rightarrow \delta \cdot$. Multiplying out and neglecting higher order terms results in the following:

$$
\mathbf{x}^{\prime}=\left[\begin{array}{ccc}
1 & \delta \psi & \delta \theta \\
\delta \psi & 1 & \delta \phi \\
\delta \theta & \delta \phi & 1
\end{array}\right] \mathbf{x}
$$

Combining equations (13) and (14) along with our definition of protection levels given by Figure 1 (where now Lat. PL = $\left(x^{\prime}-w_{v}\right) / 2$, Lon. PL $=\left(y^{\prime}-l_{v}\right) / 2$, and $\left.\mathrm{VPL}=z^{\prime} / 2\right)$ gives the combined protection level as a function of position and orientation errors:

$$
\begin{aligned}
\text { Lat. } \mathrm{PL} & =\delta_{\text {lat }}+\left(\delta_{\text {lon }}+l_{v} / 2\right) \delta \psi+\delta_{\text {vert }} \delta \theta \\
\text { Lon. } \mathrm{PL} & =\delta_{\text {lon }}+\left(\delta_{\text {lat }}+w_{v} / 2\right) \delta \psi+\delta_{\text {vert }} \delta \phi \\
\mathrm{VPL} & =\delta_{\text {vert }}+\left(\delta_{\text {lat }}+w_{v} / 2\right) \delta \theta+\left(\delta_{\text {lon }}+l_{v} / 2\right) \delta \phi
\end{aligned}
$$

To give a sense of how the above equations scale, Figure 17 shows the lateral, longitudinal, and vertical protection level inflation as a function of attitude error for the freeway alert limits given in Table VIII. This assumes the same angular error in each direction and shows how quickly these inflate our protection levels. The allocation of position and orientation error budgets is ultimately a design choice which will be examined in more detail in Section VII 


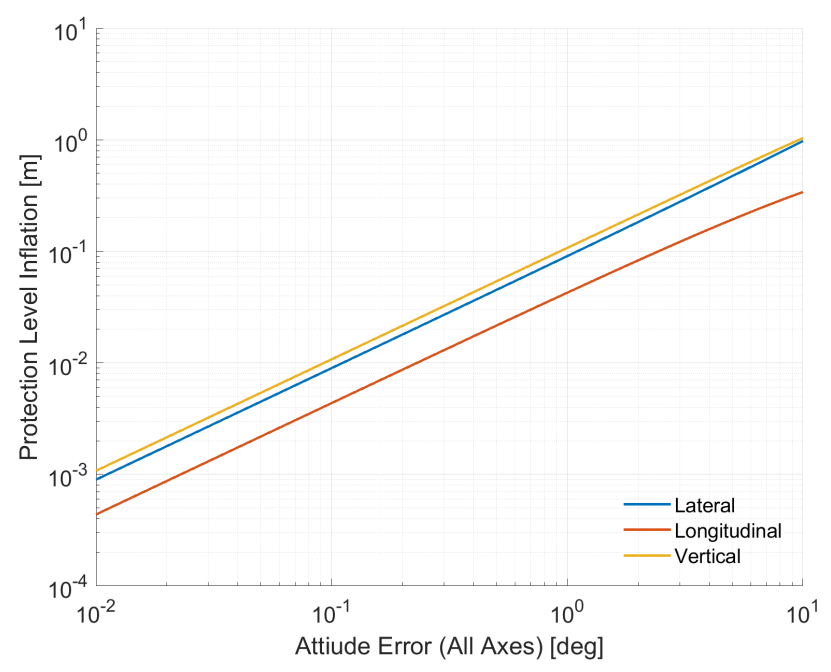

Fig. 17. Example of protection level inflation as a function of attitude error (on all axes). This assumes passenger vehicle design limits and the highway/interchange alert limits given in Table VIII

\section{UPDATE FREQUENCY}

The time required between successive localization updates (latency) is a function of the vehicle speed and road geometry. The longer the update interval, the larger the distance between localization updates. For example, at $100 \mathrm{~km} / \mathrm{h}(62 \mathrm{mph})$, $10 \mathrm{~Hz}$ gives localization updates 2.7 meters apart, the lane width of some local streets. At $130 \mathrm{~km} / \mathrm{h}(80 \mathrm{mph}), 10 \mathrm{~Hz}$ yields 3.6 meters between successive updates, the width of a freeway lane. The relationship between vehicle speed, sampling rate, and the distance between samples is given in Figure 18. A lag in position update leads directly to further uncertainty in localization, predominantly in the longitudinal direction. Hence this lag must be managed such that it does not become a dominant factor.

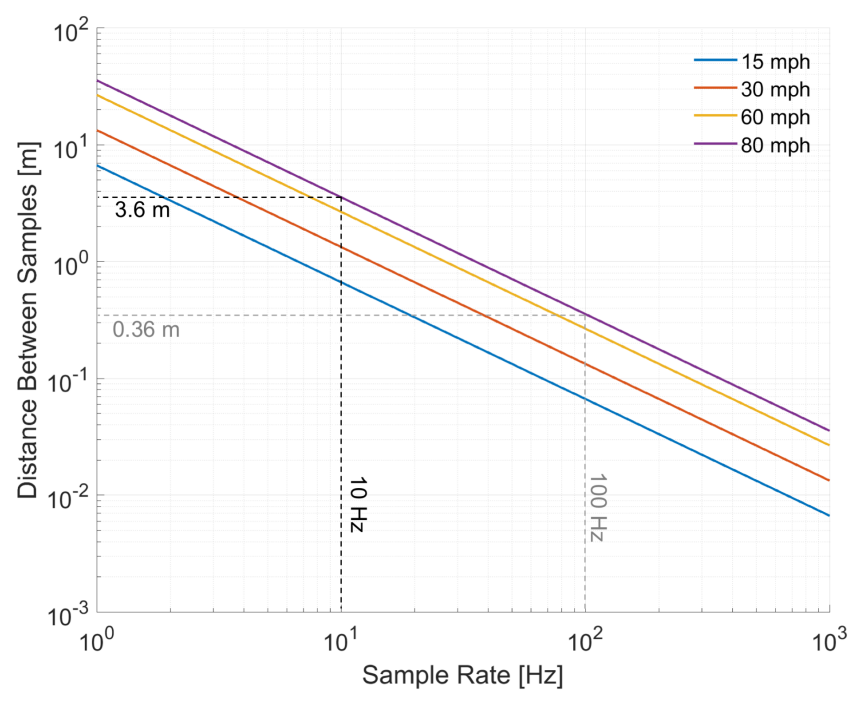

Fig. 18. The relationship between sample rate, speed, and distance between samples.
Section III showed that highway operation requires a longitudinal protection level of 1.5 meters. At highway speeds of up to $130 \mathrm{~km} / \mathrm{h}(80 \mathrm{mph}), 100 \mathrm{~Hz}$ gives rise to 0.36 meter spacing between successive position updates and $200 \mathrm{~Hz}$ gives 0.17 meters. This drives our requirement since we want the contribution of this uncertainty to be only a small component of our protection level. An update of $200 \mathrm{~Hz}$ corresponds to a successive point spacing one tenth of our chosen alert limit and seems most appropriate. An update of $200 \mathrm{~Hz}$ may seem fast for localization technologies, where LiDAR and GNSS typically output position updates at $10-20 \mathrm{~Hz}$, but when combined with an inertial measurement unit (IMU), rates of $200 \mathrm{~Hz}$ can be achieved. This requirement is ultimately that on the system as a whole, not each piece individually.

The update rate can be throttled based on speed, slowing during low speed driving to save compute and power, and to increase range. For example, at $100 \mathrm{~km} / \mathrm{h}(62 \mathrm{mph})$ on the freeway, one-tenth the longitudinal alert limit can be achieved at $150 \mathrm{~Hz}$. However, as was shown in Section IIII, operation on local streets requires tighter requirements. Even on local streets where sharp turns are taken at $15 \mathrm{~km} / \mathrm{h}(10 \mathrm{mph})$, we require our alert limit to be 0.33 meters, one tenth of this number at this speed corresponds to $125 \mathrm{~Hz}$. Hence, $100 \mathrm{~Hz}$ or greater appears to be the appropriate update rate for both highway and local street operation.

\section{LOCALIZATION REQUIREMENTS DESIGN}

In this section we will summarize the design process for allocating localization requirements. This balances allowable errors in position and attitude. The results are summarized in Tables IX and X

Our design equations are based on (15), where we require protection levels $\leq$ alert limits. This guarantees knowledge that we are within the desired lane and on the appropriate road level to the degree of safety needed for operation. These design equations are as follows:

$$
\begin{aligned}
\delta_{\text {lat }}+\left(\delta_{\text {lon }}+l_{v} / 2\right) \delta \psi+\delta_{\text {vert }} \delta \theta & \leq \text { Lat. } \mathrm{AL} \\
\delta_{\text {lon }}+\left(\delta_{\text {lat }}+w_{v} / 2\right) \delta \psi+\delta_{\text {vert }} \delta \phi & \leq \mathrm{Lon} . \mathrm{AL} \\
\delta_{\text {vert }}+\left(\delta_{\text {lat }}+w_{v} / 2\right) \delta \theta+\left(\delta_{\text {lon }}+l_{v} / 2\right) \delta \phi & \leq \mathrm{VAL}
\end{aligned}
$$

In the above, our protection levels are written as a function of both position and orientation errors as developed in Section $\mathrm{V}$. These coupled equations must satisfy the constraints developed in Sections III and IV] which describe the total allowable lateral, longitudinal, and vertical errors (alert limits) as a function of the road geometry and vehicle dimensions. These alert limits are summarized in Table VIII

We are most constrained in horizontal components, especially the lateral direction, so we will use this as our driving constraint equation. Assuming angular errors are allowed to be the same in each direction, namely $\delta \theta=\delta \phi=\delta \psi=\delta \lambda$, the lateral component of (16) simplifies to:

$$
\delta_{\text {lat }}+\left(\delta_{\text {lon }}+\delta_{\text {vert }}+l_{v} / 2\right) \delta \lambda \leq \text { Lat. } \mathrm{AL}
$$

Section [II] showed that for passenger vehicle limits, the sum of allowable longitudinal and vertical errors for freeway operation 
turns out to be approximately half the vehicle length $l_{v} / 2$, so a good rule of thumb is:

$$
\delta_{\text {lat }}+l_{v} \delta \lambda \leq \text { Lat. } \mathrm{AL}
$$

Since the limiting $l_{v}$ for passenger vehicles is 5.8 meters and the lateral alert limit was set at 0.72 meters for freeway operation (see Table VIII), the acceptable error in orientation $\delta \lambda$ must be less than 0.1 radians (5.73 degrees) otherwise we quickly exceed this limit. A reasonable choice for $\delta \lambda$ seems to be an orientation error of 1.5 degrees ( 0.03 radians) which leads to a contribution of 0.15 meters when scaled by $l_{v}$. This leads to a required lateral positioning error $\delta_{\text {lat }}$ limit of 0.57 meters to meet our combined requirement.

Local streets have more stringent requirements. Though longitudinal requirements are tighter, equation (18) is still a reasonable approximation of how errors scale. Since the lateral alert limit in these conditions is 0.33 meters for passenger vehicle limits (see Table VIII), we require nearly a threefold improvement compared to freeway design numbers. This puts us around 0.5 degrees of orientation error $\delta \lambda$ which leads to an error contribution of 0.05 meters when scaled by $l_{v}$. This leaves us with an allowable lateral position error $\delta_{\text {lat }}$ of 0.29 meters.

Using design equations (16 18) as a guide, along with the geometric bounds given in Table VIII representing the total combined alert limits, bounds for position and orientation errors can be produced. To overload notation, we will also refer to these position and orientation bounds as alert limits. Using these numbers, we can obtain an approximation for the $95 \%$ accuracy requirements by assuming a Gaussian distribution. Though the error distribution of the localization system may not be Gaussian, when thinking of this in Gaussian terms, $\left(1-10^{-8}\right)$ is $99.999999 \%$ or approximately $5.73 \sigma$. This gives us a sense when evaluating localization technologies of what statistics we should be looking for in terms of metrics like $95 \%$ accuracy performance $(1.96 \sigma)$. In other words, when deriving hard error bounds (the alert limits) on localization requirements to a degree of certainty of $\left(1-10^{-8}\right)$ we will take $95 \%(1.96 \sigma)$ accuracy as approximately one third of this number since $1.96 \sigma / 5.73 \sigma=1 / 2.92$. This relationship is shown visually in Figure 19 for lateral freeway positioning requirements. Ultimately, there will be other considerations on the distribution of localization errors including smoothness of output and additional parameters such as acceleration and jerk which are relevant to controlling the vehicle for passenger comfort [49], [50].

Putting all of the information developed so far together, requirements can be broken down by road type and operation. The requirements for freeways and interchanges are summarized in Table IX for a variety of vehicles ranging from midsize to large 'dualie' pickup trucks. This includes position and attitude alert limits, 95\% accuracy, and the integrity requirements developed in Section II. The requirements for local roads are summarized in Table $\overline{\mathrm{X}}$ for passenger vehicles. Though speeds are lower, the road geometry is tighter, leading to more stringent requirements on localization.

These results indicate that highway operations will require lateral accuracies in the 0.2 meters $(95 \%)$ range, a conclusion

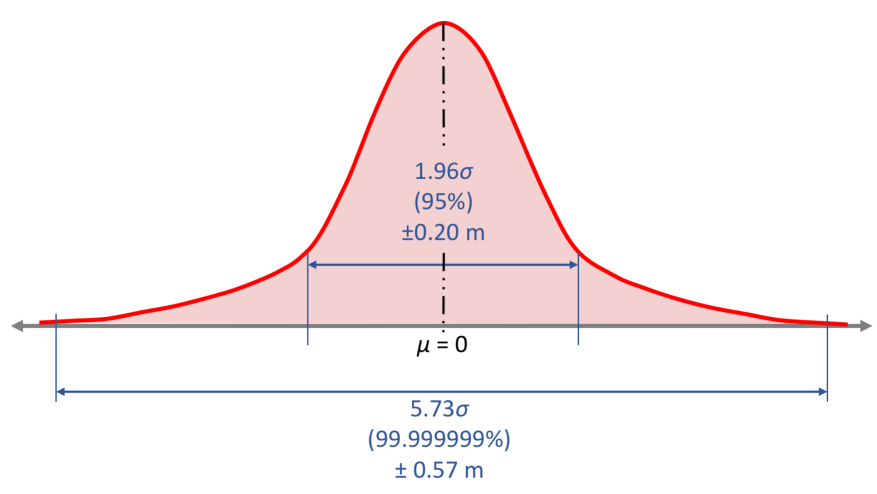

Fig. 19. The desired error distribution for lateral positioning on freeways for passenger vehicle dimension limits, assuming a Gaussian distribution. This shows the $95 \%$ accuracy at 0.20 meters and hard error bound at $0.57 \mathrm{~m}$ at $99.999999 \%$ which is a probability of $\left(1-10^{-8}\right)$.

which matches the requirements for lane departure warning systems [21], [51]. Longitudinal and vertical requirements are more forgiving, with numbers in the 0.4 meters $(95 \%)$ range, with pointing requirements in each direction of 0.5 degrees (0.01 radians) (95\%). Operations on local roads require lateral and longitudinal accuracies in the 0.1 meters $(95 \%)$ range with pointing requirements of 0.17 degrees (3 milliradians) (95\%).

\section{CONCLUSION}

The localization requirements for autonomous vehicles represent the next order of magnitude in accuracy needs for widespread deployment. Here, localization requirements in terms of accuracy, integrity, and latency were developed based on vehicle dimensions, road geometry standards, and a target level of safety. Integrity risk allocation leveraged the approach taken in civil aviation where similar requirements on localization are derived at $10^{-8}$ probability of failure per hour of operation. Combining this with road geometry standards, requirements emerge for different road types and operation. For passenger vehicles operating on freeways, the result is a required lateral error bound of $0.57 \mathrm{~m}(0.20 \mathrm{~m}, 95 \%)$, a longitudinal bound of $1.40 \mathrm{~m}(0.48 \mathrm{~m}, 95 \%)$, a vertical bound of $1.30 \mathrm{~m}(0.43 \mathrm{~m}, 95 \%)$, and an attitude bound in each direction of $1.50 \mathrm{deg}(0.51 \mathrm{deg}, 95 \%)$. On local streets, the road geometry makes requirements more stringent where lateral and longitudinal error bounds of $0.29 \mathrm{~m}(0.10 \mathrm{~m}, 95 \%)$ are needed with an orientation requirement of $0.50 \mathrm{deg}(0.17 \mathrm{deg}, 95 \%)$.

It should be emphasized that these requirements are not for one particular localization method or technology, but for the system comprised of many pieces. In addition, the system must meet both 95\% accuracy requirements and safety integrity level requirements in all weather and traffic conditions where operation is intended. Demonstrating the desired integrity levels cannot be proven by vehicle testing alone, where reasonable sized testing fleets would have to be driven for potentially decades to obtain the necessary data [52]. Hence, innovative certification solutions may be necessary [52], [53]. In addition, the localization requirements presented here are with respect to knowledge of where roads and lanes are in the world. Hence, 
TABLE IX

LOCALIZATION REQUIREMENTS FOR US FREEWAY OPERATION WITH INTERCHANGES. THIS ASSUMES MINIMUM LANE WIDTHS OF 3.6 METERS AND ALLOWABLE SPEEDS UP TO $137 \mathrm{KM} / \mathrm{H}(85 \mathrm{MPH})$.

\begin{tabular}{|c|c|c|c|c|c|c|c|c|c|}
\hline \multirow{2}{*}{ Vehicle Type } & \multicolumn{4}{|c|}{ Accuracy $(95 \%)$} & \multicolumn{4}{|c|}{ Alert Limit } & \multirow{2}{*}{$\begin{array}{l}\text { Prob. of Failure } \\
\text { (Integrity) }\end{array}$} \\
\hline & $\begin{array}{l}\text { Lateral } \\
{[\mathrm{m}]}\end{array}$ & $\begin{array}{l}\text { Long. } \\
{[\mathrm{m}]}\end{array}$ & $\begin{array}{l}\text { Vertical } \\
{[\mathrm{m}]}\end{array}$ & $\begin{array}{l}\text { Attitude* } \\
\text { [deg] }\end{array}$ & $\begin{array}{c}\text { Lateral } \\
{[\mathrm{m}]}\end{array}$ & $\begin{array}{l}\text { Long. } \\
{[\mathrm{m}]}\end{array}$ & $\begin{array}{c}\text { Vertical } \\
{[\mathrm{m}]}\end{array}$ & $\begin{array}{l}\text { Attitude* } \\
\text { [deg] }\end{array}$ & \\
\hline Mid-Size & 0.24 & 0.48 & 0.44 & 0.51 & 0.72 & 1.40 & 1.30 & 1.50 & $\begin{array}{l}10^{-9} / \text { mile } \\
\left(10^{-8} / \text { hour }\right)\end{array}$ \\
\hline Full-Size & 0.23 & 0.48 & 0.44 & 0.51 & 0.66 & 1.40 & 1.30 & 1.50 & $\begin{array}{l}10^{-9} / \text { mile } \\
\left(10^{-8} / \text { hour }\right)\end{array}$ \\
\hline Standard Pickup & 0.21 & 0.48 & 0.44 & 0.51 & 0.62 & 1.40 & 1.30 & 1.50 & $\begin{array}{l}10^{-9} / \text { mile } \\
\left(10^{-8} / \text { hour }\right)\end{array}$ \\
\hline $\begin{array}{l}\text { Passenger Vehicle } \\
\text { Limits }\end{array}$ & 0.20 & 0.48 & 0.44 & 0.51 & 0.57 & 1.40 & 1.30 & 1.50 & $\begin{array}{l}10^{-9} / \text { mile } \\
\left(10^{-8} / \text { hour }\right)\end{array}$ \\
\hline 6-Wheel Pickup & 0.14 & 0.48 & 0.44 & 0.51 & 0.40 & 1.40 & 1.30 & 1.50 & $\begin{array}{l}10^{-9} / \text { mile } \\
\left(10^{-8} / \text { hour }\right)\end{array}$ \\
\hline
\end{tabular}

*Error in each direction (roll, pitch, and heading).

TABLE X

LOCALIZATION REQUIREMENTS FOR US LOCAL ROADS. THIS ASSUMES LANES 3.0 METERS WIDE WITH A MINIMUM CURVATURE OF 20 METERS OR 3.3 METERS WIDE WITH MINIMUM CURVATURE OF 10 METERS.

\begin{tabular}{|c|c|c|c|c|c|c|c|c|c|}
\hline \multirow{2}{*}{ Vehicle Type } & \multicolumn{4}{|c|}{ Accuracy $(95 \%)$} & \multicolumn{4}{|c|}{ Alert Limit } & \multirow{2}{*}{$\begin{array}{l}\text { Prob. of Failure } \\
\text { (Integrity) }\end{array}$} \\
\hline & $\begin{array}{l}\text { Lateral } \\
{[\mathrm{m}]}\end{array}$ & $\begin{array}{l}\text { Long. } \\
{[\mathrm{m}]}\end{array}$ & $\begin{array}{l}\text { Vertical } \\
{[\mathrm{m}]}\end{array}$ & $\begin{array}{l}\text { Attitude* } \\
\text { [deg] }\end{array}$ & $\begin{array}{l}\text { Lateral } \\
{[\mathrm{m}]}\end{array}$ & $\begin{array}{l}\text { Long. } \\
{[\mathrm{m}]}\end{array}$ & $\begin{array}{l}\text { Vertical } \\
{[\mathrm{m}]}\end{array}$ & $\begin{array}{l}\text { Attitude* } \\
\text { [deg] }\end{array}$ & \\
\hline Mid-Size & 0.15 & 0.15 & 0.48 & 0.17 & 0.44 & 0.44 & 1.40 & 0.50 & $\begin{array}{l}10^{-9} / \text { mile } \\
\left(10^{-8} / \text { hour }\right)\end{array}$ \\
\hline Full-Size & 0.13 & 0.13 & 0.48 & 0.17 & 0.38 & 0.38 & 1.40 & 0.50 & $\begin{array}{l}10^{-9} / \text { mile } \\
\left(10^{-8} / \text { hour }\right)\end{array}$ \\
\hline Standard Pickup & 0.12 & 0.12 & 0.48 & 0.17 & 0.34 & 0.34 & 1.40 & 0.50 & $\begin{array}{l}10^{-9} / \text { mile } \\
\left(10^{-8} / \text { hour }\right)\end{array}$ \\
\hline $\begin{array}{l}\text { Passenger Vehicle } \\
\text { Limits }\end{array}$ & 0.10 & 0.10 & 0.48 & 0.17 & 0.29 & 0.29 & 1.40 & 0.50 & $\begin{array}{l}10^{-9} / \text { mile } \\
\left(10^{-8} / \text { hour }\right)\end{array}$ \\
\hline
\end{tabular}

*Error in each direction (roll, pitch, and heading).

these requirements are with respect to the map. The map will also have its own uncertainty $\sigma_{m a p}$ with respect to the global reference, e.g. the WGS-84 datum, as also discussed in [51]. The relationship between the vehicle's localization uncertainty in the global frame $\sigma_{\text {global }}$, its localization uncertainty relative to the map $\sigma_{\text {relative }}$, and the uncertainty of the map itself $\sigma_{\text {map }}$ with respect to the global frame is given by the following:

$$
\sigma_{\text {global }}^{2}=\sigma_{\text {relative }}^{2}+\sigma_{\text {map }}^{2}
$$

Well geo-referenced maps tied to global datums such as WGS-84 will likely be necessary for interoperability of maps between potentially many map suppliers. These maps can be made with survey-grade equipment and post-processing and could have errors much less than the real-time vehicle localization requirements.

What has been presented here are localization requirements based on the limiting road geometry. Additional requirements based on operational and other constraints will continue to evolve, but this provides a baseline. These geometrical constraints represent the worst cases; with a-priori highly detailed maps of the environment, the road geometry will be known and hence localization resources can be adjusted on the fly to meet demand and could even be a layer in the map itself. Achieving these requirements represents challenges in sensor and algorithm development along with multi-modal sensor fusion to obtain the reliability levels needed for safe operation. Some techniques involving LiDAR, radar, and cameras rely on a-priori maps and give map-relative position. Others such as GNSS give global absolute position. Combining these and other technologies and selecting those most appropriate for the desired level of autonomous operation in a way that ensures integrity for safe operation is the challenge that lays ahead.

\section{ACKNOWLEDGMENTS}

The authors would like to thank Ford Motor Company for supporting this work.

\section{REFERENCES}

[1] T. G. R. Reid, "Orbital diversity for global navigation satellite systems," Ph.D. dissertation, Stanford University, 2017. [Online]. Available: https://searchworks.stanford.edu/view/12064597

[2] P. V. H. Weems, "Accuracy of Marime Navigation," Navigation, vol. 2, no. 10, pp. 354-357, 1951. [Online]. Available: http: //doi.wiley.com/10.1002/j.2161-4296.1951.tb00481.x 
[3] R. Dippy, "Gee: a radio navigational aid," Journal of the Institution of Electrical Engineers - Part IIIA: Radiolocation, vol. 93, no. 2, pp. 468-480, 1946. [Online]. Available: http://digital-library.theiet.org/ content/journals/10.1049/ji-3a-1.1946.0131

[4] R. J. Kelly and D. R. Cusick, "Distance Measuring Equipment and its Evolving Role in Aviation," Advances in Electronics and Electron Physics, vol. 68, pp. 1-243, jan 1986. [Online]. Available: https://www.sciencedirect.com/science/article/pii/S0065253908608549

[5] S. Lo, Y. H. Chen, B. Peterson, and R. Erikson, "Distance Measuring Equipment Accuracy Performance Today and for Future Alternative Position Navigation and Timing (APNT)," in Proceedings of the 26th International Technical Meeting of The Satellite Division of the Institute of Navigation (ION GNSS 2013), Nashville, TN, 2013, pp. 711-721.

[6] T. A. Stansell, "The Navy Navigation Satellite System: Description and Status," Navigation, vol. 15, no. 3, pp. 229-243, sep 1968. [Online]. Available: http://doi.wiley.com/10.1002/j.2161-4296.1968.tb01612.x

[7] - " "Transit, the Navy Navigation Satellite System," Navigation, vol. 18, no. 1, pp. 93-109, mar 1971. [Online]. Available: http://doi.wiley.com/10.1002/j.2161-4296.1971.tb00077.x

[8] B. W. Parkinson, T. Stansell, R. Beard, and K. Gromov, "A History of Satellite Navigation," Navigation, vol. 42, no. 1, pp. 109-164, mar 1995. [Online]. Available: http://doi.wiley.com/10.1002/j.2161-4296. 1995.tb02333.x

[9] William J. Hughes Technical Center Federal Aviation Administration GPS Product Team, "Global Positioning System (GPS) Standard Positioning Service (SPS) Performance Analysis Report, Report \#72," Tech. Rep., 2011. [Online]. Available: http://www.nstb.tc.faa.gov/ reports/PAN72\{_\}0111.pdf

[10] , "Global Positioning System (GPS) Standard Positioning Service (SPS) Performance Analysis Report, Report \#32," Tech. Rep., 2001 [Online]. Available: http://www.nstb.tc.faa.gov/reports/PAN32\{_\}0101. pdf

[11] , "Global Positioning System (GPS) Standard Positioning Service (SPS) Performance Analysis Report, Report \#52," Tech. Rep., 2006. [Online]. Available: http://www.nstb.tc.faa.gov/reports/PAN52\{_\}0106. pdf

[12] (SPS) Performance Analysis Report, Report \#96," Tech. Rep., 2017. [Online]. Available: http://www.nstb.tc.faa.gov/reports/PAN96\{_\}0117. pdf

[13] F. van Diggelen and P. K. Enge, "The World's first GPS MOOC and Worldwide Laboratory using Smartphones," in Proceedings of the 28th International Technical Meeting of The Satellite Division of the Institute of Navigation (ION GNSS+ 2015), Tampa, FL, 2015, pp. $361-369$.

[14] SAE International, "Taxonomy and Definitions for Terms Related to Driving Automation Systems for On-Road Motor Vehicles (J3016B)," Tech. Rep., 2018. [Online]. Available: https://www.sae.org/standards/ content/j3016\{_\}201806/

[15] J. Hughes, "Car Autonomy Levels Explained," 2018 [Online]. Available: http://www.thedrive.com/sheetmetal/15724/ what-are-these-levels-of-autonomy-anyway

[16] E. Ackerman, "Cadillac Adds Level 2 Highway Autonomy With Super Cruise," 2017. [Online]. Available: https://spectrum.ieee.org/cars-that-think/transportation/self-driving/ cadillac-adds-level-2-highway-autonomy-with-super-cruise

[17] M. Harris, "Waymo Filings Give New Details on Its Driverless Taxis," 2018. [Online]. Available: https://spectrum.ieee.org/cars-that-think/transportation/ self-driving/waymo-filings-give-new-details-on-its-driverless-taxis

[18] C. Basnayake, T. Williams, P. Alves, and G. Lachapelle, Can GNSS drive V2X?, oct 2010, vol. 21. [Online]. Available: http: //gpsworld.com/transportationroadcan-gnss-drive-v2x-10611/

[19] National Highway Traffic Safety Administration and Department of Transportation, "Federal Motor Vehicle Safety Standards; V2V Communications, Docket No. NHTSA20160126, RIN 2127AL55," Washington, DC, Tech. Rep., 2017.

[20] S. Stephenson, "Automotive applications of high precision GNSS," Ph.D. dissertation, University of Nottingham, dec 2016. [Online]. Available: http://eprints.nottingham.ac.uk/38716/

[21] Y. Feng, C. Wang, and C. Karl, "Determination of Required Positioning Integrity Parameters for Design of Vehicle Safety Applications," in Proceedings of the 2018 International Technical Meeting of The Institute of Navigation, Reston, Virginia, 2018, pp. 129-141.

[22] Insurance Institute for Highway Safety and Highway Loss Data Institute, "Fatality Facts." [Online]. Available: http://www.iihs.org/iihs/ topics/t/general-statistics/fatalityfacts/state-by-state-overview
[23] U.S. Department of Transportation, "Transportation Statistics Annual Report (TSAR) 2017," Washington, DC, 2017.

[24] S. Singh, "Critical reasons for crashes investigated in the National Motor Vehicle Crash Causation Survey (Traffic Safety Facts Crash Stats. Report No. DOT HS 812 115)," National Highway Traffic Safety Administration, Washington, DC, Tech. Rep., 2015. [Online]. Available: https://crashstats.nhtsa.dot.gov/Api/Public/ViewPublication/812115

[25] C. V. Oster and J. S. Strong, "Analyzing road safety in the United States," Research in Transportation Economics, vol. 43, no. 1, pp. 98-111, jul 2013. [Online]. Available: https://www.sciencedirect.com/ science/article/pii/S0739885912002090

[26] A. C. Busch, "Methodology for Establishing A Target Level of Safety," Department of Transportation, Federal Aviation Administration, Atlantic City Airport, NJ, Tech. Rep., 1985. [Online]. Available: http://www.tc.faa.gov/its/worldpac/techrpt/cttn85-36.pdf

[27] R. J. Kelly and J. M. Davis, "Required Navigation Performance (RNP) for Precision Approach and Landing with GNSS Application," Navigation, vol. 41, no. 1, pp. 1-30, mar 1994. [Online]. Available: http://doi.wiley.com/10.1002/j.2161-4296.1994.tb02320.x

[28] B. Roturier, E. Chatre, and J. Ventura-Traveset, "The SBAS integrity concept standardised by ICAO: Application to EGNOS," Navigation Paris, vol. 49, no. 196, pp. 65-77, 2001.

[29] L. Blincoe, T. R. Miller, E. Zaloshnja, and B. A. Lawrence, "The Economic and Societal Impact of Motor Vehicle Crashes, 2010 (Revised)," U.S. Department of Transportation, National Highway Traffic Safety Administration, Washington DC, Tech. Rep., 2015. [Online]. Available: www.ntis.gov.

[30] Oregon Department of Transportation, "2013 Crash Rates by Jurisdiction and Functional Classification," Oregon Department of Transportation, Tech. Rep., 2013. [Online]. Available: https://www.oregon.gov/ODOT/

[31] _ , "2014 Crash Rates by Jurisdiction and Functional Classification," Oregon Department of Transportation, Tech. Rep., 2014. [Online]. Available: https://www.oregon.gov/ODOT/

[32] M. Wood, N. Earnhart, and K. Kennett, "Airbag Deployment Thresholds from Analysis of the NASS EDR Database," SAE International Journal of Passenger Cars - Electronic and Electrical Systems, vol. 7, no. 1, pp. 2014-01-0496, apr 2014. [Online]. Available: http://papers.sae.org/2014-01-0496/

[33] International Maritime Organization, "Revised maritime policy and requirements for a future GNSS," 2002.

[34] J. Speidel, M. Tossaint, S. Wallner, and J. Á. Ávila-Rodríguez, "Integrity for Aviation Comparing Future Concepts," Inside GNSS, pp. 54-64, 2013.

[35] J. Marais, J. Beugin, and M. Berbineau, "A Survey of GNSSBased Research and Developments for the European Railway Signaling," IEEE Transactions on Intelligent Transportation Systems, vol. 18 , no. 10 , pp. $2602-2618$, oct 2017. [Online]. Available: http://ieeexplore.ieee.org/document/7857080/

[36] A. Filip, H. Mocek, and J. Suchanek, "Significance of the Galileo Signalin-Space Integrity and Continuity for Railway Signalling and Train Control," in 8 th World Congress on Railway Research (WCRR), Seoul, Korea, 2008.

[37] T. Reid, T. Walter, J. Blanch, and P. Enge, "GNSS Integrity in The Arctic," Navigation, vol. 63, no. 4, pp. 469-492, dec 2016. [Online] Available: http://doi.wiley.com/10.1002/navi.169

[38] E. Verhulst, "From Safety Integrity Level to Assured Reliability and Resilience Level for Compositional Safety Critical Systems." 2013.

[39] E. Verhulst and B. H. Sputh, "ARRL: A criterion for compositional safety and systems engineering: A normative approach to specifying components," in 2013 IEEE International Symposium on Software Reliability Engineering Workshops (ISSREW). IEEE, nov 2013, pp. 37-44. [Online]. Available: http://ieeexplore.ieee.org/lpdocs/epic03/ wrapper.htm?arnumber $=6688861$

[40] P. Baufreton, J. P. Blanquart, J. L. Boulanger, H. Delseny, J. C. Derrien, J. Gassino, G. Ladier, E. Ledinot, M. Leeman, and P. Quéré, "Multidomain comparison of safety standards," in Proceedings of the 5th international conference on embedded real time software and systems (ERTS-2010), Toulouse, 2010.

[41] J.-P. Blanquart, J.-M. Astruc, P. Baufreton, J.-L. Boulanger, H. Delseny, J. Gassino, G. Ladier, E. Ledinot, M. Leeman, and J. Machrouh, "Criticality categories across safety standards in different domains," in Proceedings of the 5th international conference on embedded real time software and systems (ERTS 2012), Toulouse, 2012.

[42] J. Machrouh, J.-P. Blanquart, P. Baufreton, and J.-L. Boulanger, "Cross domain comparison of System Assurance," in Proceedings of the 5th international conference on embedded real time software and systems (ERTS-2012), Toulouse, 2012. 
[43] P. Kafka, "The Automotive Standard ISO 26262, the Innovative Driver for Enhanced Safety Assessment \& Technology for Motor Cars," Procedia Engineering, vol. 45, pp. 2-10, jan 2012. [Online]. Available: https://www.sciencedirect.com/science/article/pii/S1877705812031244

[44] American Association of State Highway and Transportation Officials, "A Policy on Geometric Design of Highways and Streets," 2001.

[45] U.S. Department of Transportation Federal Highway Administration, "Federal Size Regulations for Commercial Motor Vehicles," Washington, DC, p. 17, 2017.

[46] United States Department of Transportation and Federal Highway Administration, "Roundabouts: An Informational Guide," McLean, VI, Tech. Rep., 2000. [Online]. Available: https://www.fhwa.dot.gov/ publications/research/safety/00067/00067.pdf

[47] Washington State Department of Transportation, "Design Manual," Olympia, WA, 2017.

[48] United States Department of Transportation Federal Highway Administration, "Manual on Uniform Traffic Control Devices for Streets and Highways," 2009.

[49] C. C. Smith, D. Y. McGehee, and A. J. Healey, "The Prediction of Passenger Riding Comfort From Acceleration Data," Journal of Dynamic Systems, Measurement, and Control, vol. 100, no. 1, p. 34, mar 1978.

[50] R. O'Brien, P. Iglesias, and T. Urban, "Vehicle lateral control for automated highway systems," IEEE Transactions on Control Systems Technology, vol. 4, no. 3, pp. 266-273, may 1996. [Online]. Available: http://ieeexplore.iee. $.0 r g / d o c u m e n t / 491200 /$

[51] EDMap Consortium, "Enhanced digital mapping project: final report," Brussels, 2004.

[52] N. Kalra and S. M. Paddock, "Driving to safety: How many miles of driving would it take to demonstrate autonomous vehicle reliability?" Transportation Research Part A: Policy and Practice, vol. 94, pp. 182-193, dec 2016. [Online]. Available: https://www.sciencedirect.com/ science/article/pii/S0965856416302129

[53] P. Koopman and M. Wagner, "Autonomous Vehicle Safety: An Interdisciplinary Challenge," IEEE Intelligent Transportation Systems Magazine, vol. 9, no. 1, pp. 90-96, 2017. [Online]. Available: http://ieeexplore.ieee.org/document/7823109/

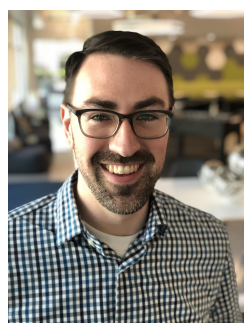

Dr. Tyler G. R. Reid is a Research Engineer on the Controls and Automated Systems team at Ford Motor Company working in the area of localization and mapping. He is also a lecturer at Stanford University in Aeronautics and Astronautics. He received his Ph.D. ('17) and M.S. ('12) in Aeronautics and Astronautics from Stanford where he worked in the GPS Research Lab. In 2015, he worked as a Software Engineer at Google's Street View. He completed his B.Eng. in Mechanical Engineering ('10) at McGill University.

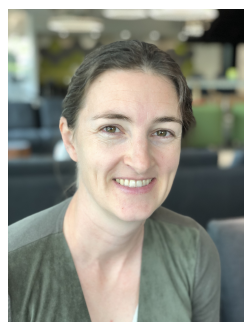

Dr. Sarah E. Houts is a Research Engineer at Ford Autonomous Vehicles LLC, working on mapping and localization technologies for Autonomous Vehicles. She received her Ph.D. ('16) and M.Sc. ('08) in Aeronautics and Astronautics from Stanford University, where she worked in the Aerospace Robotics Lab focusing on localization and path planning for autonomous underwater vehicles. She also received her B.S. ('06) in Aerospace Engineering from UC San Diego.
Robert Cammarata is a Supervisor for the Autonomous Vehicle Systems Engineering (AVSE) team at Ford Autonomous Vehicles LLC. One aspect of his current responsibilities include overseeing and developing systems engineering strategies and functional safety activities for autonomous vehicle systems. He achieved a Master of Science in Electrical Engineering from the University of Michigan. Prior to employment at Ford, he held positions at Chrysler, Mercedes Benz RDNA, kVA, Apple, Tesla, and GM developing embedded software, embedded architectures, functional safety analysis and cybersecurity solutions for traditional, hybrid, electrified, and autonomous vehicles.

Dr. Graham Mills is a Research Engineer at Ford Autonomous Vehicles, LLC specializing in LiDAR calibration and mapping. He received his $\mathrm{PhD}$ ('15) in Geomatics and Geology from Queen's University, where his research focused on automated classification of rock surface geometry in LiDAR scans.

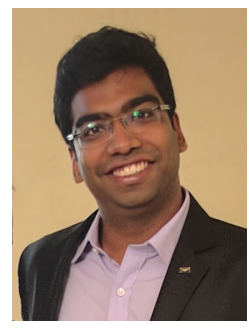

Siddharth Agarwal is a Research Engineer at Ford Autonomous Vehicles LLC. He received his M.S. ('15) in Electrical Engineering from Texas A\&M University with a research focus on Unmanned Aerial Vehicles. His areas of interest include localization, mapping, and multi-agent autonomous systems.

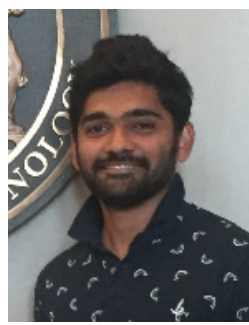

Ankit Vora Ankit Vora is a Research Engineer at Ford Autonomous Vehicles LLC working in the area of mapping and localization. His research focus is on SLAM, state estimation for autonomous vehicles, localization, and place recognition. He received his M.S.E. ('16) in Mechanical Engineering, specializing in Robotics, from the University of Pennsylvania.

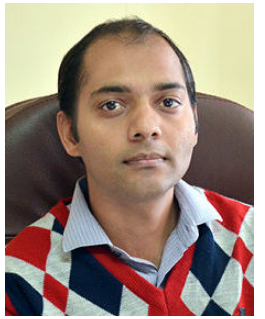

Dr. Gaurav Pandey is a Technical Expert in the Controls and Automated Systems department of Ford Motor Company. He is currently leading the mapping and localization group at Ford and is working on developing localization algorithms for SAE level 3 and level 4 autonomous vehicles. Prior to Ford, Dr. Pandey was an Assistant Professor at the Electrical engineering department of Indian Institute of Technology (IIT) Kanpur in India. At IIT Kanpur he was part of two research groups (i) Control and Automation, (ii) Signal Processing and Communication. His research focus is on visual perception for autonomous vehicles and mobile robots using tools from computer vision, machine learning, and information theory. He did is B-Tech from IIT Roorkee in 2006 and completed his Ph.D. from University of Michigan, Ann Arbor in December 2013. 